\title{
Site selection for floating offshore wind turbines in Japanese coasts by quantitative risk assessment
}

\author{
Megumi Shiokari $^{1}$ (D) Shigeru Tabeta ${ }^{2} \cdot$ Shigesuke Ishida $^{3}$
}

Received: 31 August 2018 / Accepted: 20 November 2018 / Published online: 3 December 2018

(c) The Author(s) 2018

\begin{abstract}
Floating offshore wind turbines (FOWTs) are now at the stage of demonstration experiments in Japan. They have a specific risk of "drift", which is negligible for bottom-fixed offshore wind turbines. Taking account of the risk of drift, it is necessary to consider the spatial relations between a FOWT and surrounding sea-lanes, coastal facilities, and ecosystem, in addition to the profitability and stakes in fishing industry, when selecting an appropriate site for installing the FOWT. In this paper, the authors propose the method of site selection for installing a FOWT by quantitative risk assessment, taking account of the spatial relations between the FOWT and surrounding sea-lanes, coastal facilities and ecosystem. Based on the calculation results in the case study of the quantitative risk assessment, the following procedure is recommended: first, extract the area where the risks related to the sea-lane are small enough, and second, select the position within the extracted area with the smallest risk of collision with coastal facilities or ecosystem in case of drift of the FOWT by quantitative evaluation of the risk distribution under the environmental conditions in the area. The proposed procedure is commonly applicable in most areas of Japanese coast.
\end{abstract}

Keywords Floating offshore wind turbines $\cdot$ Quantitative risk assessment $\cdot$ Safety assessment $\cdot$ Site selection

\section{Introduction}

At present, almost all the offshore wind turbines for commercial use are bottom-fixed type all over the world. In Japan, profitability and stakes in fishing industry have been mainly considered when selecting an appropriate site for installing an offshore wind turbine. On the other hand, floating offshore wind turbines (FOWTs) are now at the stage of demonstration experiments in Japan [1-3]. They have a

Megumi Shiokari

shiokari@nmri.go.jp

Shigeru Tabeta

tabeta@k.u-tokyo.ac.jp

Shigesuke Ishida

ishida@ioes.saga-u.ac.jp

1 National Maritime Research Institute, National Institute of Maritime, Port and Aviation Technology, 6-38-1 Shinkawa, Mitaka City, Tokyo 181-0004, Japan

2 The University of Tokyo, 5-1-5 Kashiwanoha, Kashiwa City, Chiba 277-8563, Japan

3 Saga University, 1 Honjo-machi, Saga City, Saga 840-8502, Japan specific risk of "drift" which is negligible for the bottomfixed type. Taking account of the risk of drift, it is also necessary to consider the spatial relations between a FOWT and surrounding sea-lanes, coastal facilities and ecosystem.

There are some existing safety standards for FOWTs [4, 5] and some previous researches that assessed the risk of "progressive drift" of FOWTs in a wind farm, which is a situation that one FOWT drifts and collides with the other ones resulting in the drifts of the multiple FOWTs $[6,7]$. However, the previous researches mainly focused on the safety of the turbine itself, not on the damages of surrounding ships, coastal facilities or ecosystem. In this paper, the authors propose the method of site selection for installing a FOWT by quantitative risk assessment, taking account of the spatial relations between a FOWT and surrounding sealanes, coastal facilities and ecosystem.

\section{Risk analyses for a FOWT}

The authors considered some risk events specific for a FOWT, i.e., breaking of a mooring chain and dredging anchor, which might result in drift of a FOWT, and flooding 


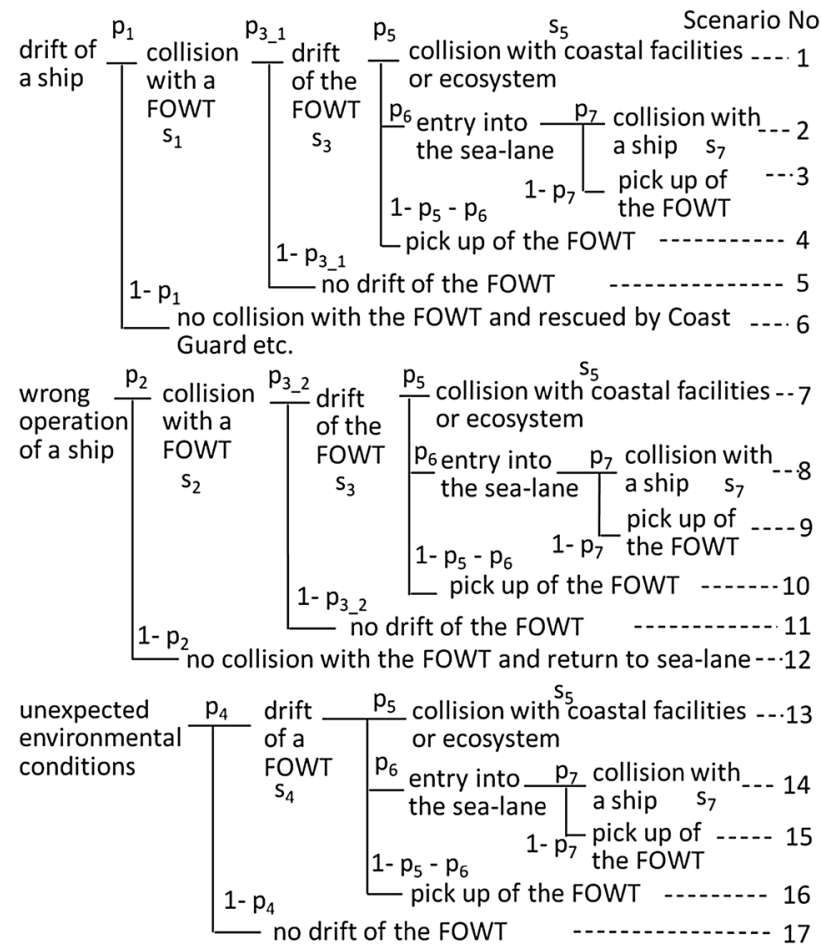

Fig. 1 Risk scenarios corresponding to "drift of a FOWT"

in a floating body of a FOWT. We conducted fault tree analysis (FTA) and event tree analysis (ETA) to identify the causes and the consequences of the above risk events. In the analyses, we neglected the events which were not liable to occur when the FOWT was conforming to the relevant design standards, and identified the event sequences which were so-called "beyond expectations". Then we developed the event sequences, hereafter called "risk scenarios", corresponding to "drift of a FOWT", which might cause damages to surrounding ships, coastal facilities or ecosystem as shown in Fig. 1. In this figure, the symbol of $p_{\mathrm{x}}$ means the probability of occurrence of the right event after the left event occurred and the symbol of $s_{\mathrm{x}}$ means the financial loss owing to the occurrence of the corresponding event. The symbol of $s_{6}$ is not included in this figure because the event "entry into the sea-lane" itself does not seem to cause any damage. These symbols and their meanings are shown in Table 1.

\section{Method of quantitative safety risk assessment}

\subsection{Analysis area and candidate area for installing a FOWT}

The analysis area and the candidate area are set as shown in

Fig. 2. The analysis area is the virtual Japanese coastal sea
Table 1 Symbols of probabilities and financial losses

\begin{tabular}{|c|c|}
\hline$p_{1}$ & $\begin{array}{l}\text { Conditional probability of collision between a drifting ship } \\
\text { and the FOWT when the ship is drifting }\end{array}$ \\
\hline$p_{2}$ & $\begin{array}{l}\text { Conditional probability of collision between a wrongly oper- } \\
\text { ated ship and the FOWT when the ship is sailing in the } \\
\text { sea-lane }\end{array}$ \\
\hline$p_{3 \_1}$ & $\begin{array}{l}\text { Conditional probability of drift of the FOWT after the colli- } \\
\text { sion with a drifting ship }\end{array}$ \\
\hline$p_{3 \_2}$ & $\begin{array}{l}\text { Conditional probability of drift of the FOWT after the colli- } \\
\text { sion with a wrongly operated ship }\end{array}$ \\
\hline$p_{4}$ & $\begin{array}{l}\text { Probability of drift of the FOWT by unexpected environmen- } \\
\text { tal conditions }\end{array}$ \\
\hline$p_{5}$ & $\begin{array}{l}\text { Conditional probability of collision between the drifting } \\
\text { FOWT and a coastal facility or ecosystem when the FOWT } \\
\text { is drifting }\end{array}$ \\
\hline$p_{6}$ & $\begin{array}{l}\text { Conditional probability of entry of the drifting FOWT into the } \\
\text { sea-lane when the FOWT is drifting }\end{array}$ \\
\hline$p_{7}$ & $\begin{array}{l}\text { Conditional probability of collision between the drifting } \\
\text { FOWT and a ship after the entry of the drifting FOWT into } \\
\text { the sea-lane }\end{array}$ \\
\hline$s_{1}$ & $\begin{array}{l}\text { Financial loss of the FOWT owing to the damage by collision } \\
\text { with a drifting ship }\end{array}$ \\
\hline$s_{2}$ & $\begin{array}{l}\text { Financial loss of the FOWT owing to the damage by collision } \\
\text { with a wrongly operated ship }\end{array}$ \\
\hline$s_{3}$ & $\begin{array}{l}\text { Financial loss of the FOWT owing to the drift by collision } \\
\text { with a ship }\end{array}$ \\
\hline$s_{4}$ & $\begin{array}{l}\text { Financial loss of the FOWT owing to the drift by unexpected } \\
\text { environmental conditions }\end{array}$ \\
\hline$s_{5}$ & $\begin{array}{l}\text { Financial losses of coastal facilities or ecosystem owing to } \\
\text { collision with the FOWT }\end{array}$ \\
\hline$s_{7}$ & $\begin{array}{l}\text { Financial loss of a ship in the sea-lane owing to collision with } \\
\text { the FOWT }\end{array}$ \\
\hline
\end{tabular}

area, which includes a coastal facility or ecosystem and a sea-lane. The candidate area is where we can make the risk maps, i.e., the spatial distributions of the quantitative risks for respective risk scenarios, and select an appropriate site for installing a FOWT. The spatial resolution for the analysis is $1000 \mathrm{~m}$ for respective horizontal directions, i.e., $x$ and $y$. In the analysis area, the centerline of the sea-lane means the average of the distances between ships and the coastline in a lateral ( $x$-direction) ship distribution.

\subsection{Targeted FOWT}

The target of the analysis is 5.0 MW wind turbine on a triangle-shaped floating body. Figure 3 shows the outline of the turbine and the floating body. Tables 2 and 3 show the principal particulars of the wind turbine and the floating body, respectively. Those were decided by referring to Bauer et al. [8] and National Maritime Research Institute et al. [9], respectively. The floating body is moored on the sea ground by the catenary system with three mooring chains. Table 4 shows the principal particulars of the mooring chains, which 


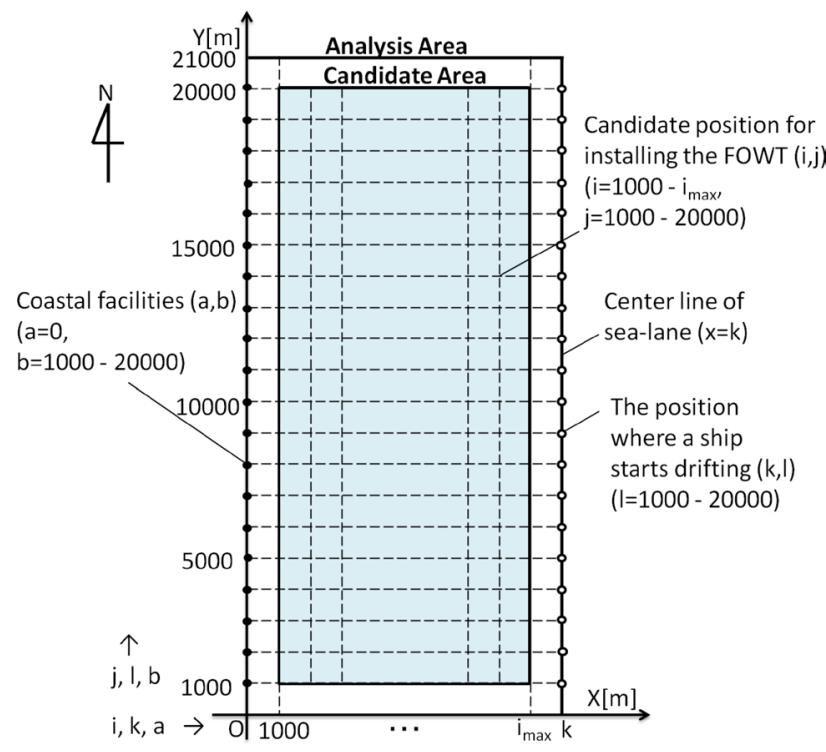

Fig. 2 Analysis area and candidate area for the FOWT installation

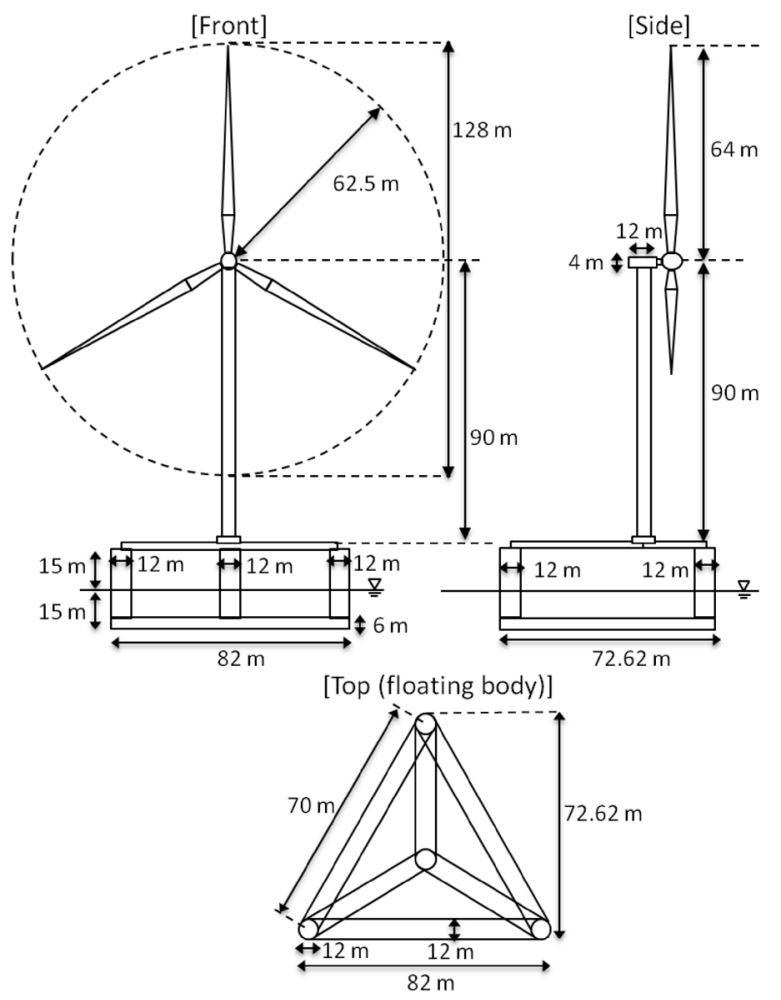

Fig. 3 Outline of the turbine and floating body $[8,9]$

were decided by referring to National Maritime Research Institute et al. [9]. In Table 4, the minimum breaking load (MBL) is calculated for each environmental condition by multiplying environmental loads with 50-year return period and the safety factor of 2.0 (in the case of quasi-static
Table 2 Principal particulars of the wind turbine [8]

\begin{tabular}{ll}
\hline Rotor diameter $(\mathrm{m})$ & 128 \\
Blade length $(\mathrm{m})$ & 62.5 \\
$\begin{array}{l}\text { Hub height from the base } \\
\text { of tower }(\mathrm{m})\end{array}$ & 90.0 \\
Nacelle height $(\mathrm{m})$ & 4.00 \\
Nacelle length (m) & 12.5 \\
Nacelle width (m) & 4.00 \\
Number of blades & 3 \\
\hline
\end{tabular}

Table 3 Principal particulars of the floating body [9]

\begin{tabular}{ll}
\hline Total length (m) & 72.62 \\
Total width (m) & 82.00 \\
Distance between columns (m) & 70.00 \\
Column height (m) & 30.00 \\
Column width (m) & 12.00 \\
Draft (m) & 15.00 \\
Lower hull width (m) & 12.00 \\
Lower hull height (m) & 6.00 \\
Displacement (fresh water) (ton) & 15,582 \\
\hline
\end{tabular}

Table 4 Principal particulars of the mooring chain [5, 9]

\begin{tabular}{ll}
\hline Install water depth $(\mathrm{m})$ & 232.50 \\
Number of mooring chains & 3 \\
Chain length $(\mathrm{m})$ & 600.00 \\
Young's modulus $\left(\mathrm{ton} / \mathrm{mm}^{2}\right)$ & 5.7000 \\
Chain diameter $(\mathrm{mm})$ & 138.70 \\
Weight in the water $(\mathrm{kg} / \mathrm{m})$ & 365.72 \\
MBL for each environmental condition $(\mathrm{kN})$ & \\
No. 1 & 16,122 \\
No. 2 & 8416.8 \\
No. 3 & 5993.5 \\
\hline
\end{tabular}

analysis) [5]. In the case study in Sect. 4, the initial tension is set at 1/10 of each MBL. Each environmental condition will be explained in Sect. 4.1.

\subsection{Assessment procedures}

First, the authors selected a position where the FOWT was assumed to be installed in the candidate area. Second, we assessed the risks quantitatively at the position by calculating the probabilities and the financial losses of all the risk events and multiply the probabilities and the total of the financial losses in each risk scenario. Finally, we conducted the assessments at every position in the candidate area and we made the risk maps for selecting the appropriate site for installing the FOWT. 


\subsection{Calculation methods of each risk event probability}

\subsubsection{Probability of collision between a drifting ship and the FOWT}

The conditional probability of collision between a drifting ship and the FOWT when the ship is drifting, i.e., $p_{1}$, is calculated by the following formulae:
On the other hand, $\overrightarrow{\mathrm{v}_{\mathrm{dw}}}$ is also expressed as follows:

$\overrightarrow{v_{\mathrm{dw}}}=\overrightarrow{v_{\mathrm{d}}}-\overrightarrow{v_{\mathrm{g}}}$,

where $\overrightarrow{v_{\mathrm{d}}}$ is the velocity of wind-driven current and $\overrightarrow{v_{\mathrm{g}}}$ is the absolute velocity of drift of the ship. When it is assumed that wind-driven current is negligible, formula (5) is reexpressed as follows:

$\overrightarrow{v_{\mathrm{g}}}=-\overrightarrow{v_{\mathrm{dw}}}$.

$p_{1}(i, j)=\frac{1}{n_{\mathrm{S}}} \sum_{k} \sum_{l} \sum_{\theta_{\mathrm{w}}} \sum_{v_{\mathrm{w}}} \sum_{\theta_{\mathrm{c}}} \sum_{v_{\mathrm{c}}} \sum_{s}\left\{\delta_{\mathrm{SDW}}\left(i, j, k, l, \theta_{\mathrm{w}}, v_{\mathrm{w}}, \theta_{\mathrm{c}}, v_{\mathrm{c}}, s\right) \times p_{\mathrm{d}}\left(\theta_{\mathrm{w}}, v_{\mathrm{w}}, \theta_{\mathrm{c}}, v_{\mathrm{c}}, s\right)\right\}$,

$\delta_{\mathrm{SDW}}=\left\{\begin{array}{ll}1 & \left(\theta_{\mathrm{R}}(i, j, k, l) \leq \theta_{\mathrm{S}}\left(\theta_{\mathrm{w}}, v_{\mathrm{w}}, \theta_{\mathrm{c}}, v_{\mathrm{c}}, s\right) \leq \theta_{\mathrm{L}}(i, j, k, l)\right) \\ 0 & \text { (others) }\end{array}\right.$,

where $i$ and $j$ are $x$ - and $y$-coordinates of the point where the FOWT is installed, respectively, $n_{\mathrm{s}}$ is the number of points where a ship can start drifting, $k$ and $l$ are $x$ - and $y$-coordinates of the point where a ship starts drifting, respectively, $\theta_{\mathrm{w}}$ is a wind direction, $v_{\mathrm{w}}$ is a wind speed, $\theta_{\mathrm{c}}$ is a current direction, $v_{\mathrm{c}}$ is a current speed, $s$ is a ship size (gross tonnage (GT) or dead weight tonnage (DWT)), $\delta_{\mathrm{SDW}}\left(i, j, k, l, \theta_{\mathrm{w}}, v_{\mathrm{w}}, \theta_{\mathrm{c}}, v_{\mathrm{c}}, s\right)$ is the judgment function of collision between a drifting ship and the FOWT, $p_{\mathrm{d}}\left(\theta_{\mathrm{w}}, v_{\mathrm{w}}, \theta_{\mathrm{c}}, v_{\mathrm{c}}, s\right)$ is the joint probability of the case that the ship size is $s$ and the combination of environmental conditions is $\left(\theta_{\mathrm{w}}, v_{\mathrm{w}}, \theta_{\mathrm{c}}, v_{\mathrm{c}}\right), \theta_{\mathrm{R}}(i, j, k, l)$ and $\theta_{\mathrm{L}}(i, j, k, l)$ are the directions of the right and left edges of the FOWT from the point where the ship starts drifting, respectively, and $\theta_{\mathrm{S}}\left(\theta_{\mathrm{w}}, v_{\mathrm{w}}, \theta_{\mathrm{c}}, v_{\mathrm{c}}, s\right)$ is the drift direction of the ship.

If $\theta_{\mathrm{S}}$ is within $\theta_{\mathrm{R}}$ and $\theta_{\mathrm{L}}$, it is judged that the collision between the drifting ship and the FOWT occurs and $\delta_{\mathrm{SDW}}$ is determined to be 1 . Otherwise, $\delta_{\mathrm{SDW}}$ is determined to be 0 . The calculation method of $\theta_{\mathrm{S}}$ with steady state is as follows.

First, the drift velocity of the ship by wind is determined by balancing wind drag force above the water with resistance force underwater [10]. The wind drag force, $\overrightarrow{F_{\mathrm{w}}}$, and the water resistance force, $\overrightarrow{F_{\mathrm{dw}}}$, are expressed as follows:

$\overrightarrow{F_{\mathrm{w}}}=\frac{1}{2} \rho_{\mathrm{a}} A_{\mathrm{as}} C_{\mathrm{Dw}} \overrightarrow{v_{\mathrm{w}}}\left|\overrightarrow{v_{\mathrm{w}}}\right|$,

$\overrightarrow{F_{\mathrm{dw}}}=\frac{1}{2} \rho_{\mathrm{w}} A_{\mathrm{ws}} C_{\mathrm{Ddw}} \overrightarrow{v_{\mathrm{dw}}}|\overrightarrow{\mathrm{dw}}|$,

where $\rho_{\mathrm{a}}$ is air density, $\rho_{\mathrm{w}}$ is sea water density, $A_{\mathrm{as}}$ is projected area of the ship above the water, $A_{\mathrm{ws}}$ is projected area of the ship underwater, $C_{\mathrm{Dw}}$ is wind drag coefficient, $C_{\mathrm{Ddw}}$ is water resistance coefficient, $\overrightarrow{v_{\mathrm{w}}}$ is wind velocity and $\overrightarrow{v_{\mathrm{dw}}}$ is relative velocity of drift of the ship to the velocity of winddriven current. The relative velocity, $\overrightarrow{v_{\mathrm{dw}}}$, is determined by balancing these two formulae.
Second, it is assumed that the drift velocity of the ship by current is the same as current velocity, $\overrightarrow{v_{c}}$, and the wave drift force is negligible. Then the drift speed of the ship by wind and current, $\overrightarrow{v_{\mathrm{S}}}$, is determined as follows, and $\theta_{\mathrm{S}}$ is determined as the direction of $\overrightarrow{v_{\mathrm{s}}}$ :

$\overrightarrow{v_{\mathrm{s}}}=\overrightarrow{v_{\mathrm{g}}}+\overrightarrow{v_{\mathrm{c}}}$.

In these calculations, it is assumed that wind is blowing at the transverse direction. Thus, $C_{\mathrm{Dw}}$ and $C_{\mathrm{Ddw}}$ are determined as 0.1 and 0.8 , respectively, referring to Ueno et al. [11]. $A_{\text {as }}=L^{2}$ and $A_{\text {ws }}=L d$ in Ueno et al. [11], where $L$ and $d$ are the length overall and the draft of the ship, respectively.

\subsubsection{Probability of collision between a wrongly operated ship and the FOWT}

In the previous research, "passing vessel collision frequency for a platform" was formulated [12-14]. We simplified and revised the formulae and defined $P_{\mathrm{CPP}}$ as annual frequency of collision between a wrongly operated ship and the FOWT as follows:

$P_{\mathrm{CPP}}(i)=N \times P_{\mathrm{CC}}(i) \times P_{\mathrm{FSIR}}$,

where $N$ is annual number of ships in the sea-lane, $P_{\mathrm{CC}}$ is the probability that a ship is on a collision course at the point where the ship can observe the FOWT, visually or on radar (generally, 12 nautical miles before the FOWT [14]) and $P_{\mathrm{FSIR}}$ is the probability that the ship itself does not initiate some action to avoid a collision with the FOWT (Failure of Ship Initiated Recovery).

$P_{\mathrm{CC}}$ is calculated by considering the lateral distribution of the ships traveling in the sea-lane and determined as follows:

$P_{\mathrm{CC}}(i)=P\left[D_{\mathrm{L}}(i)-\frac{B}{2} \leq x \leq D_{\mathrm{L}}(i)+\frac{B}{2}\right]=\int_{D_{\mathrm{L}}(i)-\frac{B}{2}}^{D_{\mathrm{L}}(i)+\frac{B}{2}} f_{\mathrm{LD}}(x) \mathrm{d} x$, 
where $D_{\mathrm{L}}$ is the distance between the FOWT and the centerline of the sea-lane and it varies depending on $i$, i.e., $x$-coordinate of the position where the FOWT is installed, $B$ is the width of the floating body of the FOWT and $f_{\mathrm{LD}}$ is the probability density of the ships traveling in the sea-lane.

The value of $P_{\mathrm{FSIR}}$ was estimated to be $1.76 \times 10^{-4}$ by the back analysis, according to the information by Haugen et al. $[12,13]$ : calculation results of annual collision frequency between ships and a platform; and calculation conditions of the width of the platform and the annual number of ships.

The symbol $p_{2}$ denotes the conditional probability of collision between a wrongly operated ship and the FOWT when the ship is sailing in the sea-lane, and the above formula (8) can be rewritten as follows using $p_{2}$ :

$P_{\mathrm{CPP}}(i)=N \times p_{2}(i)$,

$\therefore p_{2}(i)=P_{\mathrm{CC}}(i) \times P_{\mathrm{FSIR}}$.

\subsubsection{Probability of drift of the FOWT after the collision with a drifting ship}

The conditional probability of drift of the FOWT after the collision with a drifting ship, i.e., $p_{3}$, is calculated by formulae (12) and (13). Because this probability depends on the environmental forces and the collision speed of the drifting ship, it cannot be calculated independent of $p_{1}$. Therefore, $p_{1}$ and " $p_{1} \times p_{3} \_$" should be calculated together at first, then " $p_{1} \times p_{3 \_}$" should be divided by $p_{1}$ to obtain the value of $p_{3_{-}}$: (if the loss of energy at collision could be ignored, the kinetic energy is the same as that of the drifting ship just before the collision).

If all the energy generated by the environmental forces and the collision exceeds the absorbable energy of all the mooring chains, it is judged that the drift of the FOWT occurs and $\delta_{\mathrm{WD} 1}$ is determined to be 1 . Otherwise, $\delta_{\mathrm{WD} 1}$ is determined to be 0 .

Using the formulae for the tension of a catenary mooring chain [15] with the parameters in Table 4, we got the relation between the horizontal movement distance of the FOWT from the initial position and the increment of the horizontal tension from the initial horizontal tension of the mooring chain for each environmental condition. Figure 4 shows the relation under the environmental conditions No. 1. In this figure, $E_{\text {env }}$ means the sum of $E_{\text {envf }}$ and $E_{\text {envs }}$, and $E_{\mathrm{b}}$ means the maximum allowable energy not to break the chain in case of collision with a ship.

Because the environmental forces keep working on the FOWT and the ship after the collision, the energy of movement of them after the collision does not include only the kinetic energy of them when they move together $\left(E_{\mathrm{ds}}\right)$, but also the energy by environmental forces $\left(E_{\text {envd }}\right)$. If $E_{\mathrm{ds}}$ exceeds $E_{\mathrm{b}}$ in Fig. 4, the mooring chain will be broken and it is assumed that if $E_{\mathrm{ds}}$ exceeds three times of $E_{\mathrm{b}}$, the FOWT starts drifting.

In fact, the actual breaking load of the mooring chain is, in general, higher than the MBL at the initial condi-

$p_{3 \_1}(i, j)=\frac{1}{p_{1}(i, j)} \frac{1}{n_{\mathrm{S}}} \sum_{k} \sum_{l} \sum_{\theta_{\mathrm{w}}} \sum_{v_{\mathrm{w}}} \sum_{\theta_{\mathrm{c}}} \sum_{v_{\mathrm{c}}} \sum_{s}\left\{\delta_{\mathrm{WD} 1}\left(i, j, k, l, \theta_{\mathrm{w}}, v_{\mathrm{w}}, \theta_{\mathrm{c}}, v_{\mathrm{c}}, s\right) \times p_{\mathrm{d}}\left(\theta_{\mathrm{w}}, v_{\mathrm{w}}, \theta_{\mathrm{c}}, v_{\mathrm{c}}, s\right)\right\}$,

$\delta_{\mathrm{WD} 1}=\left\{1\left(E_{\mathrm{all}} \leq\left\{\begin{array}{l}E_{\text {envf }}\left(\theta_{\mathrm{w}}, v_{\mathrm{w}}, \theta_{\mathrm{c}}, v_{\mathrm{c}}\right) \\ +E_{\text {envs }}\left(i, j, k, l, \theta_{\mathrm{w}}, v_{\mathrm{w}}, \theta_{\mathrm{c}}, v_{\mathrm{c}}, s\right) \\ +E_{\text {envd }}\left(i, j, k, l, \theta_{\mathrm{w}}, v_{\mathrm{w}}, \theta_{\mathrm{c}}, v_{\mathrm{c}}, s\right) \\ +E_{\mathrm{ds}}\left(i, j, k, l, \theta_{\mathrm{w}}, v_{\mathrm{w}}, \theta_{\mathrm{c}}, v_{\mathrm{c}}, s\right)\end{array}\right\}\right)\right.$,

where $\delta_{\mathrm{WD} 1}\left(i, j, k, l, \theta_{\mathrm{w}}, v_{\mathrm{w}}, \theta_{\mathrm{c}}, v_{\mathrm{c}}, s\right)$ is the judgment function of drift of the FOWT after the collision with a drifting ship, $E_{\text {all }}$ is the absorbable energy by movements of all the mooring chains of the FOWT, $E_{\text {envf }}\left(\theta_{\mathrm{w}}, v_{\mathrm{w}}, \theta_{\mathrm{c}}, v_{\mathrm{c}}\right)$ is the energy of environmental forces that the FOWT receives, $E_{\text {envs }}\left(i, j, k, l, \theta_{\mathrm{w}}, v_{\mathrm{w}}, \theta_{\mathrm{c}}, v_{\mathrm{c}}, s\right)$ is the energy of environmental forces that the ship receives accompanied with the FOWT after the collision, $E_{\text {envd }}\left(i, j, k, l, \theta_{\mathrm{w}}, v_{\mathrm{w}}, \theta_{\mathrm{c}}, v_{\mathrm{c}}, s\right)$ is the energy of movement of the ship and the FOWT after the collision by environmental forces that the ship and the FOWT receive, $E_{\mathrm{ds}}\left(i, j, k, l, \theta_{\mathrm{w}}, v_{\mathrm{w}}, \theta_{\mathrm{c}}, v_{\mathrm{c}}, s\right)$ is the kinetic energy of the ship and the FOWT when they move together after the collision tion. Then the actual breaking load changes over time and becomes lower than the MBL owing to aging degradation and it is difficult to estimate the change of the breaking load.

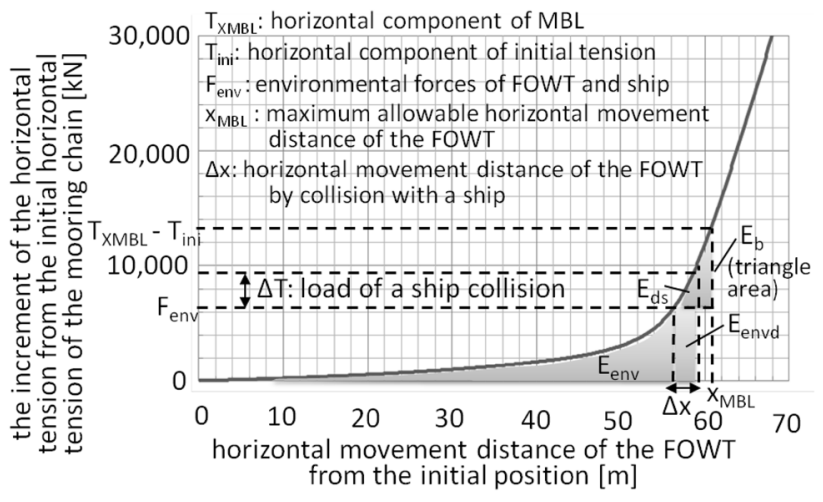

Fig. 4 Relation between the horizontal movement distance of the FOWT from the initial position and the increment of the horizontal tension from the initial horizontal tension of the mooring chain under the environmental conditions No. 1 
Therefore, we assume that the breaking load of the mooring chain equals to the MBL in this study. This assumption is also applied to the calculation of $p_{3 \_}$and $p_{4}$.

\subsubsection{Probability of drift of the FOWT after the collision with a wrongly operated ship}

The conditional probability of drift of the FOWT after the collision with a wrongly operated ship, i.e., $p_{3 \_}$, is calculated by the following formulae:
However, it is difficult to estimate the probability that the environmental loads exceed the MBL. Because the values associated with 100-year return period are not so much higher than those with 50-year return period, the environmental loads by 100 -year values do not exceed the MBL. In this calculation, 100-year values are estimated by the forecast values for 20 years in the real sea area [16], but there is a limitation to estimate the values associated with longer return period than 100 years. Therefore, it is difficult to find the return period of the environmental conditions by which the loads exceed the MBL.

$p_{3 \_2}=\sum_{\theta_{\mathrm{w}}} \sum_{v_{\mathrm{w}}} \sum_{\theta_{\mathrm{c}}} \sum_{v_{\mathrm{c}}} \sum_{\mathrm{s}} \sum_{\mathrm{v}}\left\{\delta_{\mathrm{WD} 2}\left(\theta_{\mathrm{w}}, v_{\mathrm{w}}, \theta_{\mathrm{c}}, v_{\mathrm{c}}, s, v\right) \times p_{\mathrm{w}}\left(\theta_{\mathrm{w}}, v_{\mathrm{w}}, \theta_{\mathrm{c}}, v_{\mathrm{c}}, s, v\right)\right\}$,

$\delta_{\mathrm{WD} 2}=\left\{1\left(E_{\text {all }} \leq\left\{\begin{array}{l}E_{\text {envf }}\left(\theta_{\mathrm{w}}, v_{\mathrm{w}}, \theta_{\mathrm{c}}, v_{\mathrm{c}}\right) \\ +E_{\text {envd }}\left(\theta_{\mathrm{w}}, v_{\mathrm{w}}, \theta_{\mathrm{c}}, v_{\mathrm{c}}, s, v\right) \\ +E_{\mathrm{ds}}\left(\theta_{\mathrm{w}}, v_{\mathrm{w}}, \theta_{\mathrm{c}}, v_{\mathrm{c}}, s, v\right)\end{array}\right\}\right)\right.$,

where $\delta_{\mathrm{WD} 2}\left(\theta_{\mathrm{w}}, v_{\mathrm{w}}, \theta_{\mathrm{c}}, v_{\mathrm{c}}, s, v\right)$ is the judgment function of drift of the FOWT after the collision with a wrongly operated ship, $p_{\mathrm{w}}\left(\theta_{\mathrm{w}}, v_{\mathrm{w}}, \theta_{\mathrm{c}}, v_{\mathrm{c}}, s, v\right)$ is the joint probability of the case that the ship's size is $s$, the ship's speed is $v$ and the combination of environmental conditions is $\left(\theta_{\mathrm{w}}, v_{\mathrm{w}}, \theta_{\mathrm{c}}, v_{\mathrm{c}}\right)$. $E_{\text {envs }}$ is not included in this formula because a wrongly operated ship can move away from the FOWT after the collision, while a drifting ship with the broken engine cannot.

The relation shown in Fig. 4 is also valid for formula (15), where $E_{\text {env }}$ equals to $E_{\text {envf }}$. As well as in Sect. 3.4.3, it is assumed that if $E_{\mathrm{ds}}$ exceeds three times of $E_{\mathrm{b}}$, it is judged that drift of the FOWT occurs and $\delta_{\mathrm{WD} 2}$ is determined to be 1. Otherwise, $\delta_{\mathrm{WD} 2}$ is determined to be 0 .

In the case of $p_{3 \_}$, all the energy generated by collision is dependent on the relation between the position where the ship starts drifting and the position of the FOWT. On the other hand, all the energy in formula (15) is independent of the positions of the FOWT and a ship. Therefore, $p_{3 \_}$is independent of the position of the FOWT $(i, j)$ and the value of $p_{32}$ is uniform in the candidate area.

\subsubsection{Probability of drift of the FOWT by unexpected environmental conditions}

One of the causes of the drift of a FOWT is break of mooring chain by unexpected environmental conditions exceeding the design conditions. For the design of mooring chains for a FOWT, the environmental loads with 50-year return period are used for the calculation of the MBL as mentioned above.
Given the above reason, it is difficult to estimate the probability of break of a mooring chain by unexpected environmental conditions. Accordingly, in this study, it is assumed that a mooring chain breaks at the probability of $10^{-4}$ year $^{-1}$ referring to the standard by ISO [17]. The FOWT has three mooring chains and when all the chains break, the FOWT starts drifting, but it is difficult to estimate the probability of breaking the other chains when one of them has already broken because the probability seems to be different from the probability in the sound condition. However, when the severe environmental forces, which can break a mooring chain, continue to affect the FOWT, all the mooring chains are affected by the forces and it is supposed that, after breaking one of the chains, the other chains are easily broken. Then, in this study, it is assumed that the probability of drift of the FOWT by unexpected environmental conditions is $10^{-4}$ year $^{-1}$.

This probability is independent of the position where the FOWT is installed because the environmental conditions are uniform in the candidate area. Furthermore, it is assumed that each chain breaks by the same cause: in other words, it is not considered the case that one of the chains breaks by unexpected environmental conditions and the others break by collision with a ship.

Then probability of drift of the FOWT by unexpected environmental conditions, i.e., $p_{4}$ (unit: year ${ }^{-1}$ ), is defined as follows:

$p_{4}=1.0 \times 10^{-4}$.

\subsubsection{Probability of collision between the drifting FOWT and a coastal facility or ecosystem}

The conditional probability of collision between the drifting FOWT and a coastal facility or ecosystem when the FOWT is drifting, i.e., $p_{5}$, is calculated by the following formulae: 
$p_{5}(i, j)=\sum_{\theta_{w}} \sum_{v_{w}} \sum_{\theta_{c}} \sum_{v_{c}}\left\{\delta_{\mathrm{WDF}}\left(a, b, i, j, \theta_{\mathrm{w}}, v_{\mathrm{w}}, \theta_{\mathrm{c}}, v_{\mathrm{c}}\right) \times p_{\mathrm{f}}\left(\theta_{\mathrm{w}}, v_{\mathrm{w}}, \theta_{\mathrm{c}}, v_{\mathrm{c}}\right)\right\}$,

$\delta_{\mathrm{WDF}}=\left\{\begin{array}{l}1\left(\theta_{\mathrm{Rf}}(a, b, i, j) \leq \theta_{\mathrm{f}}\left(\theta_{\mathrm{w}}, v_{\mathrm{w}}, \theta_{\mathrm{c}}, v_{\mathrm{c}}\right) \leq \theta_{\mathrm{Lf}}(a, b, i, j)\right) \\ 0 \text { (others) }\end{array}\right.$,

where $a$ and $b$ are $x$ - and $y$-coordinates of the position where a coastal facility or ecosystem exists, respectively, $\delta_{\mathrm{WDF}}\left(a, b, i, j, \theta_{\mathrm{w}}, v_{\mathrm{w}}, \theta_{\mathrm{c}}, v_{\mathrm{c}}\right)$ is the judgment function of collision between the drifting FOWT and the coastal facility or ecosystem, $p_{\mathrm{f}}\left(\theta_{\mathrm{w}}, v_{\mathrm{w}}, \theta_{\mathrm{c}}, v_{\mathrm{c}}\right)$ is the probability of the case that the combination of environmental condition is $\left(\theta_{\mathrm{w}}, v_{\mathrm{w}}, \theta_{\mathrm{c}}, v_{\mathrm{c}}\right), \theta_{\mathrm{Rf}}(a, b, i, j)$ and $\theta_{\mathrm{Lf}}(a, b, i, j)$ are the directions of the right and left edges of the coastal facility or ecosystem from the position where the FOWT starts drifting, i.e., the position where the FOWT was installed, respectively, and $\theta_{\mathrm{f}}\left(\theta_{\mathrm{w}}, v_{\mathrm{w}}, \theta_{\mathrm{c}}, v_{\mathrm{c}}\right)$ is the drift direction of the FOWT.
The projected area of the FOWT underwater depends on the current direction. We consider the 12 ways of current direction every $30^{\circ}$ and change the projected area, but it is categorized in only two kinds, i.e., "Front" and "Side" in Fig. 3. Also, water resistance coefficient is 0.8 , in the same way as in the ship [11].

\subsubsection{Probability of entry of the drifting FOWT into the sea-lane}

The conditional probability of entry of the drifting FOWT into the sea-lane when the FOWT is drifting, i.e., $p_{6}$, is calculated by the following formulae:

$p_{6}(i, j)=\sum_{\mathrm{k}} \sum_{\theta_{\mathrm{w}}} \sum_{v_{\mathrm{w}}} \sum_{\theta_{\mathrm{c}}} \sum_{v_{\mathrm{c}}}\left\{\delta_{\mathrm{WDR}}\left(k, i, j, \theta_{\mathrm{w}}, v_{\mathrm{w}}, \theta_{\mathrm{c}}, v_{\mathrm{c}}\right) \times p_{\mathrm{f}}\left(\theta_{\mathrm{w}}, v_{\mathrm{w}}, \theta_{\mathrm{c}}, v_{\mathrm{c}}\right)\right\}$,

If $\theta_{\mathrm{f}}$ is within $\theta_{\mathrm{Rf}}$ and $\theta_{\mathrm{Lf}}$, it is judged that the collision between the drifting FOWT and the coastal facility or ecosystem occurs and $\delta_{\mathrm{WDF}}$ is determined to be 1 . Otherwise, $\delta_{\mathrm{WDF}}$ is determined to be 0 . The calculation method of $\theta_{\mathrm{f}}$ with steady state is almost the same as that of $\theta_{\mathrm{S}}$, mentioned in Sect. 3.4.1. However, projected areas, i.e., $A_{\text {as }}$ and $A_{\text {ws }}$, wind drag coefficient, i.e., $C_{\mathrm{Dw}}$, and fluid resistance coefficient, i.e., $C_{\mathrm{Ddw}}$, are different because the drifting object is not the ship, but the FOWT.

The projected area of the FOWT above the water is divided into the tower part and the rotor part as shown in Fig. 3. Also, the wind drag coefficients of these parts are different. In the tower part, the wind drag coefficient is 1.2 [18]. On the other hand, in the rotor part, the coefficient depends on the wind speed. Under the cut-in wind speed, the projected area of the rotor part, i.e., $A_{\mathrm{R}}$, is calculated by multiplying length and width of the blades and the wind drag coefficient, i.e., $C_{\mathrm{DR}}$, is 1.1 [19]. Within the cut-in and the cut-out wind speed, $A_{\mathrm{R}}$ is the rotor area (circle area) and $C_{\mathrm{DR}}$ is determined based on the wind speed [20]. Above the cut-out wind speed, the rotor is in a feathering state and $A_{\mathrm{R}}$ is calculated by multiplying length and thickness of the blades and $C_{\mathrm{DR}}$ is 0.005 [21].
$\delta_{\mathrm{WDR}}=\left\{\begin{array}{l}1\left(\theta_{\mathrm{Rs}}\left(k, l_{\text {min }}, i, j\right) \leq \theta_{f}\left(\theta_{w}, v_{\mathrm{w}}, \theta_{\mathrm{c}}, v_{\mathrm{c}}\right) \leq \theta_{\mathrm{Ls}}\left(k, l_{\mathrm{max}}, i, j\right)\right) \\ 0(\text { others })\end{array}\right.$,

where $\delta_{\mathrm{WDR}}$ is the judgment function of entry of the drifting FOWT into the sea-lane $(x=k), \theta_{\mathrm{Rs}}\left(k, l_{\min }, i, j\right)$ and $\theta_{\mathrm{Ls}}\left(k, l_{\max }, i, j\right)$ are the directions of the right and left edges of the sea-lane from the point where the FOWT starts drifting, i.e., the position where the FOWT was installed, respectively, $l_{\min }$ and $l_{\max }$ are y-coordinates of the south and north edges of the sea-lane, respectively.

$\theta_{\mathrm{f}}$ is determined as well as in Sect. 3.4.6. If $\theta_{\mathrm{f}}$ is within $\theta_{\mathrm{Rs}}$ and $\theta_{\mathrm{Ls}}$, it is judged that the drifting FOWT enters into the sea-lane and $\delta_{\mathrm{WDR}}$ is determined to be 1 . Otherwise, $\delta_{\mathrm{WDR}}$ is determined to be 0 .

\subsubsection{Probability of collision between the drifting FOWT and a ship in the sea-lane}

In this paper, it is assumed that the conditional probability of collision between the drifting FOWT and a ship in the sea-lane after the drifting FOWT enters into the sea-lane, i.e., $p_{7}$, is uniform wherever the FOWT enters into the sea-lane. 
Under normal conditions, a ship can avoid collision even if the drifting FOWT enters into the sea-lane, but it is possible that a ship collides with the drifting FOWT due to a lack of watch-keeping, low visibility, or failure of equipment such as radar and GPS.

When the FOWT is drifting, it is not fixed on the sea ground and behaves like a drifting ship. Accordingly, we considered the FOWT as a ship and assumed that $p_{7}$ is approximate to the probability of collision between ships in a single voyage [22]. Then $p_{7}$ is determined as follows:

$p_{7}=3.7 \times 10^{-6}$.

\subsection{Calculation methods of the financial losses owing to each risk event}

\subsubsection{Financial loss of the FOWT owing to the damage by collision with a ship}

The symbols $s_{1}$ and $s_{2}$ denote the financial losses of the FOWT owing to the damages by collision with a drifting ship and with a wrongly operated ship, respectively. Once the FOWT is damaged, the profits by selling power generated by the FOWT will have been lost until the repair will be finished, while the repair cost will be temporary loss. Therefore, $s_{1}$ and $s_{2}$ are considered as the loss of profits due to incapability of selling power during the repair period and formulated as follows:

$s_{1}=s_{2}=W P \times R_{\mathrm{W}} \times I_{\mathrm{C}} \times T_{\mathrm{W}}$,

where WP is the rated power of the FOWT, $R_{\mathrm{W}}$ is the utilization rate of the FOWT, $I_{\mathrm{C}}$ is the price of unit electric energy and $T_{\mathrm{W}}$ is the repair period of the FOWT.

\subsubsection{Financial loss of the FOWT owing to the drift by collision with a ship or by unexpected environmental conditions}

The symbols $s_{3}$ and $s_{4}$ denote the financial losses of the FOWT owing to the drift by collision with a ship and by unexpected environmental conditions, respectively. Basically, $s_{3}$ and $s_{4}$ are considered in the same manner as $s_{1}$ and $s_{2}$, but in the case of drift of the FOWT, the FOWT will be lost totally. Therefore, $s_{3}$ and $s_{4}$ are considered as the loss of profits due to incapability of selling power during the whole remaining period of in-service and formulated as follows:

$s_{3}=s_{4}=W P \times R_{\mathrm{W}} \times I_{\mathrm{C}} \times T_{\mathrm{r}}$,

where $T_{\mathrm{r}}$ is the remaining period of in-service.

\subsubsection{Financial losses of coastal facilities or ecosystem owing to collision with the drifting FOWT}

We selected some facilities and ecosystem that seemed to be damaged by collision with the drifting FOWT and established the estimation method of the financial losses of these facilities and ecosystem as follows.

The symbol $s_{5 f}$ denotes the financial losses of fishery facilities such as floating fish preserves owing to collision with the drifting FOWT and is expressed as follows:

$s_{5 \mathrm{f}}=V_{\mathrm{a}} N_{\mathrm{a}}+m_{\mathrm{f}} V_{\mathrm{f}} N_{\mathrm{f}} N_{\mathrm{a}}$,

where $V_{\mathrm{a}}$ is the price of a fish preserve, $N_{\mathrm{a}}$ is the number of fish preserves, $m_{\mathrm{f}}$ is the weight of individual fish in the fish preserve at the time of shipment, $V_{\mathrm{f}}$ is the price of individual fish in the fish preserve at the time of shipment, and $N_{\mathrm{f}}$ is number of fish in a fish preserve.

The symbol $s_{5 \mathrm{SW}}$ denotes the financial losses of seaweed forest as ecosystem services owing to collision with the drifting FOWT and is expressed as follows:

$s_{5 \mathrm{SW}}=V_{\mathrm{SW}} A_{\mathrm{SW}} Y_{\mathrm{R}}$,

where $V_{\mathrm{SW}}$ is the value of seaweed forest per unit area and unit time as ecosystem services, $A_{\mathrm{SW}}$ is the area of damaged seaweed forest, and $Y_{\mathrm{R}}$ is the necessary period for reinstatement.

In Japan, there are some oil storage facilities installed in the sea. If the drifting FOWT collides with such facilities, it will be concerned that oil spillage will occur due to damage of the facilities. In this study, we considered the oil salvage cost and damage of seaweed as a representative of marine pollution by oil.

The oil salvage cost, $C_{\mathrm{O}}$ (unit: US\$), is expressed as follows [23]:

$C_{\mathrm{O}}=42301.0 \times\left(V_{\mathrm{O}} \times 0.85\right)^{0.7233}$,

where $V_{\mathrm{o}}$ is the amount of oil spillage (unit: $\mathrm{kL}$ ) and 0.85 is the conversion coefficient from kL to tonnage.

Considering damage of seaweed in the same way as in the above explanation of $s_{5 \mathrm{SW}}$ and combining it with $C_{\mathrm{O}}$, the financial losses owing to collision between the drifting FOWT and oil storage facilities, $s_{5 \mathrm{O}}$ is expressed as follows:

$s_{5 \mathrm{O}}=C_{\mathrm{O}}+V_{\mathrm{SW}} A_{\mathrm{SW}} Y_{\mathrm{R}}$.

\subsubsection{Financial loss of a ship in the sea-lane owing to collision with the drifting FOWT}

If the drifting FOWT enters into the sea-lane and collides with a cargo ship, the ship's hull and the cargoes could be damaged and transportation could be delayed. Regarding the damages, compensation would be made by marine insurance companies in many cases. On the other hand, once the ship's hull is 
damaged, the ship cannot transport cargoes and the ship owner cannot earn charter money until the repair will be finished.

In this study, we considered only the loss of non-operating time during the repair period and assumed that the owner of the FOWT would bear $80 \%$ of the financial loss which had been supposed to be earned during the period. The symbol $s_{7}$ denotes the amount of the financial loss and is expressed as follows:

$s_{7}=0.8 V_{\mathrm{SU}} T_{\mathrm{S}}$,

where $V_{\mathrm{SU}}$ is the charter money of the cargo ship and $T_{\mathrm{S}}$ is the repair period of the ship.

\subsection{Calculation methods of each risk}

The value of each risk can be calculated as follows:

$$
\begin{aligned}
& r_{1}=m_{\mathrm{S}} \times p_{1} \times p_{3 \_1} \times p_{5} \times\left(s_{3}+s_{5}\right), \\
& r_{2}=m_{\mathrm{S}} \times p_{1} \times p_{3 \_1} \times p_{6} \times p_{7} \times\left(s_{3}+s_{7}\right), \\
& r_{3}=m_{\mathrm{S}} \times p_{1} \times p_{3 \_1} \times p_{6} \times\left(1.0-p_{7}\right) \times s_{3}, \\
& r_{4}=m_{\mathrm{S}} \times p_{1} \times p_{3 \_1} \times\left(1.0-p_{5}-p_{6}\right) \times s_{3}, \\
& r_{5}=m_{\mathrm{S}} \times p_{1} \times\left(1.0-p_{3 \_1}\right) \times s_{1}, \\
& r_{6}=m_{\mathrm{S}} \times\left(1.0-p_{1}\right) \times 0.0, \\
& r_{7}=N \times p_{2} \times p_{3 \_2} \times p_{5} \times\left(s_{3}+s_{5}\right), \\
& r_{8}=N \times p_{2} \times p_{3 \_2} \times p_{6} \times p_{7} \times\left(s_{3}+s_{7}\right), \\
& r_{9}=N \times p_{2} \times p_{3 \_2} \times p_{6} \times\left(1.0-p_{7}\right) \times s_{3}, \\
& r_{10}=N \times p_{2} \times p_{3 \_2} \times\left(1.0-p_{5}-p_{6}\right) \times s_{3}, \\
& r_{11}=N \times p_{2} \times\left(1.0-p_{3 \_2}\right) \times s_{1}, \\
& r_{12}=N \times\left(1.0-p_{2}\right) \times 0.0, \\
& r_{13}=p_{4} \times p_{5} \times\left(s_{4}+s_{5}\right), \\
& r_{14}=p_{4} \times p_{6} \times p_{7} \times\left(s_{4}+s_{7}\right), \\
& r_{15}=p_{4} \times p_{6} \times\left(1.0-p_{7}\right) \times s_{4}, \\
& r_{16}=p_{4} \times\left(1.0-p_{5}-p_{6}\right) \times s_{4}, \\
& r_{17}=\left(1.0-p_{4}\right) \times 0.0, \\
& w 6
\end{aligned}
$$

where $r_{\mathrm{x}}$ is the value of the risk for scenario No. $\mathrm{x}$ indicated in Fig. $1, p_{\mathrm{y}}$ and $s_{\mathrm{y}}$ are the probability and financial loss of the corresponding risk event, respectively, $m_{\mathrm{S}}$ is the annual number of drifting ships in the analysis area and $N$ is the annual number of ships in the sea-lane of the area.

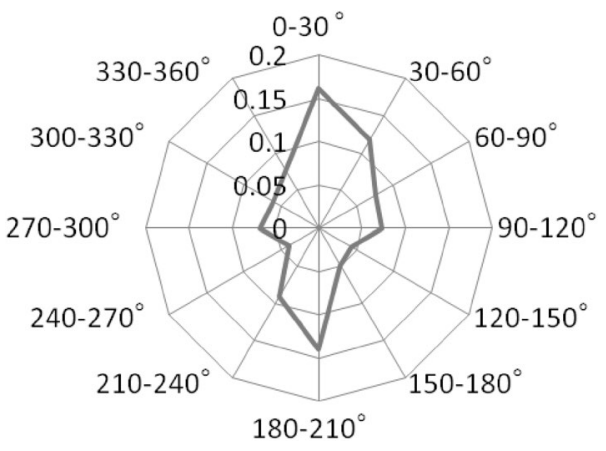

Fig. 5 Appearance frequency of wind direction at the environmental conditions No. $1\left(0^{\circ}\right.$ means wind blows from the north)

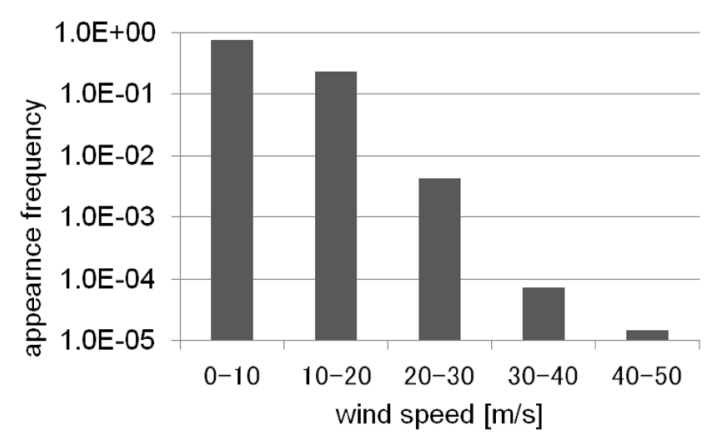

Fig. 6 Appearance frequency of wind speed at the environmental conditions No. 1

\section{Case study of quantitative assessment of safety risks}

In this section, we show the calculation conditions and calculation results in the case study of quantitative assessment of safety risks for the FOWT. Two analysis areas are used in the case study, i.e., sea areas " $A$ " and " $\mathrm{B}$ " as mentioned below. In these areas, the following data are used for the calculations: environmental conditions, ship size distribution, lateral ship distributions, annual number of drifting ships, annual number of ships, and ship speed distributions.

In these data, lateral ship distributions, annual number of drifting ships, annual number of ships and ship speed distributions are specific to the sea area. On the other hand, ship size distribution is common for the two sea areas and three kinds of environmental conditions are used in each sea area. In addition, the variety of calculation results is recognized with the combinations of four types and 20 locations of coastal facilities or ecosystem in each sea area.

When setting the calculation conditions, we neglect the ships without AIS because of a lack of available data. 
Table 5 Appearance frequency of each range of size of cargo ships [12]

\begin{tabular}{ll}
\hline Range of size (DWT), from-less than & Percentage \\
\hline $0-500$ & 1.30 \\
$500-1000$ & 2.30 \\
$1000-2000$ & 7.90 \\
$2000-3000$ & 7.30 \\
$3000-5000$ & 16.2 \\
$5000-10,000$ & 15.4 \\
$10,000-15,000$ & 2.70 \\
$15,000-30,000$ & 11.5 \\
$30,000-50,000$ & 11.8 \\
$50,000-100,000$ & 16.6 \\
$100,000-200,000$ & 6.50 \\
$200,000-300,000$ & 0.50 \\
\hline
\end{tabular}

\subsection{Calculation conditions}

\subsubsection{Environmental conditions}

The statistical database for maritime weather by National Maritime Research Institute [16] was used for the calculations. We selected three areas, which had different characteristics, in the Pacific coast of Japan. Hereafter, the environmental conditions of these sea areas are expressed as the environmental conditions No. 1-No. 3. These three environmental conditions include the appearance frequency distributions of wind and current direction for every $30^{\circ}$; wind speed for every $1 \mathrm{~m} / \mathrm{s}$ under $25 \mathrm{~m} / \mathrm{s}$, every $5 \mathrm{~m} / \mathrm{s}$ under $30 \mathrm{~m} / \mathrm{s}$ and every $10 \mathrm{~m} / \mathrm{s}$ under $50 \mathrm{~m} / \mathrm{s}$; and current speed for every $0.1 \mathrm{~m} / \mathrm{s}$ under $2.0 \mathrm{~m} / \mathrm{s}$ and every $0.5 \mathrm{~m} / \mathrm{s}$ under $3.0 \mathrm{~m} / \mathrm{s}$. For example, the appearance of frequency distributions of wind direction and wind speed at the environmental conditions No. 1 are shown in Figs. 5 and 6 , respectively.

By comparing the calculation results with various resolutions of wind and current directions for each probability, which is related to the drifting directions of ships or the FOWT, it was found that calculating every $1^{\circ}$ is needed for the precise evaluations of $p_{1}, p_{3}{ }_{1}$ and $p_{5}$, while calculating every $5^{\circ}$ is enough for the precise evaluation of $p_{6}$. For example, when calculating every $1^{\circ}$, the appearance frequencies of wind and current direction for every $30^{\circ}$ are divided equally by 30 .

\subsubsection{Ship size distribution}

It is assumed that all the ships in the sea-lane are cargo ships. The appearance frequency of each range of ship sizes was determined referring to the survey results by Takahashi et al. [24] and shown in Table 5. The central value of each range is used in the calculation. In the case of cargo ships, $L$ and $d$, as mentioned in Sect. 3.4.1, can be calculated by the ship size, $s$, as follows [24]:

$L=8.7338 \times s^{0.2945}$,

$d=\left\{\begin{array}{ll}0.3935 \times s^{0.3238} & (s \leq 30,000 \text { DWT }) \\ 0.3754 \times s^{0.3233} & (s \geq 30,000 \text { DWT })\end{array}\right.$.

\subsubsection{Lateral ship distributions in the sea-lane}

The ship distributions can be broadly divided into two types in the Pacific coast of Japan, i.e., Gaussian distribution and gamma distribution. We selected two areas and expressed them as sea area "A" and sea area "B" as the representatives of Gaussian distribution and gamma distribution, respectively.

The analyzed AIS data [25] are used for making the probability density functions of ships in these sea areas. The average distances between the coastline and ships are calculated to be $2.2 \times 10^{4} \mathrm{~m}$ and $1.3 \times 10^{4} \mathrm{~m}$ in the sea areas "A" and "B", respectively. Also, the standard deviation is calculated to be $2.8 \times 10^{3} \mathrm{~m}$ in the sea area " $\mathrm{A}$ ". On the other hand, the parameters of gamma distribution in the sea area "B" can be gained by Itoh et al. [26]: the location parameter is $5.7 \times 10^{3} \mathrm{~m}$, shape parameter is 1.0872 and scale parameter is 6720.4 .

In the case study, the line of average distance between the coastline and ships is set to be the centerline of the sealane. Accordingly, $k=22,000 \mathrm{~m}$ and $i_{\max }=21,000 \mathrm{~m}$ in the sea area "A" and $k=13,000 \mathrm{~m}$ and $i_{\max }=12,000 \mathrm{~m}$ in the sea area "B".

\subsubsection{Annual number of drifting ships}

In 2016, engine breakdowns occurred on 25 cargo ships in Japan [27] and about 1.6 million merchant ships, including domestic and international voyages, entered Japanese ports [28]. Then the frequency of engine breakdown on a cargo ship can be estimated to be $1.56 \times 10^{-5}$.

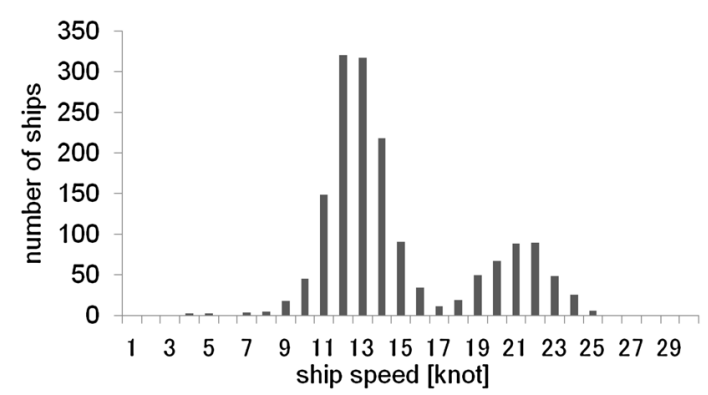

Fig. 7 Distributions of ship speeds in the sea area "A" 
It is assumed that all the engine breakdowns result in the drifts of ships. Also, the annual number of drifting ships, i.e., $m_{\mathrm{S}}$ (unit: ships year ${ }^{-1}$ ), is considered to be proportional to the annual number of ships in the sea-lane of the area, i.e., $N$ (unit: ships year ${ }^{-1}$ ). Thus, $m_{\mathrm{S}}$ is formulated as follows:

$m_{\mathrm{S}}(N)=1.56 \times 10^{-5} \times N$.

\subsubsection{Annual number of ships}

The analyzed AIS data [25] are also used for estimation of annual number of ships, i.e., $N$. There were 1612 ships in the sea area "A" for 31 days from January 1st to 31st, 2014, and annual number can be estimated to be 18,980 ships. On the other hand, there were 8027 ships in the sea area "B" for 92 days from August 1st to October 31st, 2012, and annual number can be estimated to be 31,846 ships.

\subsubsection{Ship speed distributions}

Ship speed data are also included in the analyzed AIS data [25]. The distributions of ship speeds for every 1 knot in the sea areas "A" and "B" are used for calculations. Figure 7 shows the distributions of ship speeds in the sea area "A".

\subsubsection{Financial loss of the FOWT owing to the damage by collision with a ship}

The degree of damage will depend on the speed of the ship which collides with the FOWT, but repair work will be common, an exchange of a damaged plate of the floating body of the FOWT. Therefore, the necessary period and the financial loss will not be so different whether the damage is only a crack or a large hole in a plate.

On the other hand, the repair period depends on the availability of a dock or a repairing yard. Number of docks used for repair of the FOWT is less than one for repair of a ship. Taking account of the above situations, $T_{\mathrm{W}}$ is assumed to be 44 days in formula (22), which is twice of $T_{\mathrm{S}}$ mentioned below.

Also, $R_{\mathrm{W}}$ is determined to be 0.4 , expecting the offshore wind conditions and the future technology development. $I_{\mathrm{C}}$ is determined to be 36 yen $\mathrm{kWh}^{-1}$, according to the Feed-in Tariff system in Japan [29].

\subsubsection{Financial loss of the FOWT owing to the drift by collision with a ship or by unexpected environmental conditions}

The financial loss depends on the remaining period of inservice and depends on the situations when the accident occurs. In this study, $T_{\mathrm{r}}$ in formula (23) is determined to be 10 years taking account of that the whole period of inservice is 20 years in general.

\subsubsection{Areas of coastal facilities or ecosystem}

The judgment of collision between the drifting FOWT and a coastal facility or ecosystem is dependent on the width of the floating body of the FOWT and the area of the coastal facility or ecosystem. In this case study, two types of fish preserves, i.e., for seriola and tuna, seaweed forests and oil storage facility are considered. The width of each coastal facility or ecosystem is expressed as $B_{\mathrm{x}}$ in $x$-direction and $B_{\mathrm{y}}$ in $y$-direction, and they are specified as follows.

1. Fish preserves for seriola: one fish preserve is $8 \mathrm{~m} \times 8 \mathrm{~m}$, square shape. These fish preserves are located in 2 lines in $x$-direction, 10 lines in $y$-direction and 20 fish preserves in total. The total area is $20 \mathrm{~m}\left(=B_{\mathrm{x}}\right) \times 160 \mathrm{~m}$ $\left(=B_{\mathrm{y}}\right)$ at regular intervals.

2. Fish preserves for Tuna: one fish preserve is $17 \mathrm{~m}$ of diameter, round shape. These fish preserves are located in 2 lines in $x$-direction, 3 lines in $y$-direction and six fish preserves in total. The total area is $50 \mathrm{~m}\left(=B_{\mathrm{x}}\right) \times 120 \mathrm{~m}$ $\left(=B_{\mathrm{y}}\right)$ at regular intervals.

3. Seaweed forest: the total area is 200 ha with $1000 \mathrm{~m}$ $\left(=B_{\mathrm{x}}\right) \times 2000 \mathrm{~m}\left(=B_{\mathrm{y}}\right)$.

4. Oil storage facility: it is assumed to be composed of five oil storage ships. One ship is $390 \mathrm{~m}$ (length) $\times 97 \mathrm{~m}$ (width) and there are five ships in line. The total area is $400 \mathrm{~m}\left(=B_{\mathrm{x}}\right) \times 750 \mathrm{~m}\left(=B_{\mathrm{y}}\right)$.

Each facility exists in the position $(a, b)$ with the area determined above. Because the position $(a, b)$ is in the coastline, $a=0$ and the $x$-coordinate of the east edge of facility is $B_{\mathrm{x}}$. On the other hand, the value of $\mathrm{b}$ changes from 1000 to $20,000 \mathrm{~m}$ and the $y$-coordinates of the north and south edges of facility are as follows:

$b+B_{\mathrm{y}} / 2$ (north edge),

$b-B_{\mathrm{y}} / 2$ (south edge).

Table 6 Parameters for each fish preserve [30]

\begin{tabular}{lll}
\hline & Seriola & Tuna \\
\hline Fish preserve size $(\mathrm{m})$ & Length: 8 & Diameter: 17 \\
& Width :8 & Depth: 6 \\
& Height: 8 & \\
$N_{\mathrm{a}}$ & 20 & 6 \\
$N_{\mathrm{f}}$ & 5000 & 500 \\
$V_{\mathrm{a}}\left(10^{4}\right.$ yen fish preserve $\left.^{-1}\right)$ & 400 & 500 \\
$V_{\mathrm{f}}\left(10^{4} \mathrm{yen} \mathrm{fish}^{-1}\right)$ & 0.0800 & 0.360 \\
$m_{\mathrm{f}}\left(\mathrm{kg} \mathrm{fish}^{-1}\right)$ & 3.00 & 30.0 \\
\hline
\end{tabular}


Table 7 Relations between the calculation conditions and the calculation results of each probability

\begin{tabular}{lllllll}
\hline Env. conditions & $\begin{array}{l}\text { Lateral } \\
\text { ship } \\
\text { dist. }\end{array}$ & Ship speed dist. & Ship size dist. & $\begin{array}{l}\text { Location of coastal } \\
\text { facility or ecosys- } \\
\text { tem }\end{array}$ & $\begin{array}{l}\text { Type of coastal } \\
\text { facility or eco- } \\
\text { system }\end{array}$ \\
\hline$p_{1} \quad \bigcirc \bigcirc$ & $\times \times$ & $\times \times$ & $\times \times$ & $\times \times$ & $\times \times$ \\
$p_{2} \quad \times \times$ & $\bigcirc \bigcirc$ & $\times \times$ & $\times \times$ & $\times \times$ & $\times \times$ \\
$p_{3 \_1} \Delta \bigcirc$ & $\times \times$ & $\times \times$ & $\Delta \bigcirc$ & $\times \times$ & $\times \times$ \\
$p_{3 \_2} \times \bigcirc$ & $\times \times$ & $\times \bigcirc$ & $\times \bigcirc$ & $\times \times$ & $\times \times$ \\
$p_{5}$ & $\bigcirc \bigcirc$ & $\times \times$ & $\times \times$ & $\times \times$ & $\bigcirc \bigcirc$ & $\Delta \bigcirc$ \\
$p_{6}$ & $\bigcirc \bigcirc$ & $\times \times$ & $\times \times$ & $\times \times$ & $\times \times$ & $\times \times$ \\
\hline
\end{tabular}

OThe condition having obvious impact on the probability, $\Delta$ the condition having little impact or indirect impact on the probability and $\times$ the condition having no impact on the probability. The left symbols express the extent of impact on the distribution of the probability and the right ones express the extent of impact on the magnitude of the probability

\subsubsection{Financial loss of coastal facilities or ecosystem owing to collision with the drifting FOWT}

First, as for fish preserves, the parameters in formula (24) are determined as shown in Table 6 for seriola and tuna, respectively. It is assumed that all the fish preserves are damaged by collision with the drifting FOWT.

Second, regarding seaweed forests as ecosystem services,

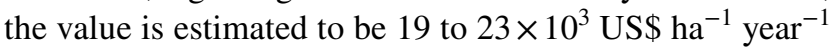
[31]. In this study, the central value is used for the case study. Also, the damaged area is assumed to be the circumscribed circle area of the triangle which is the shape of the floating body of the FOWT. Therefore, in formula

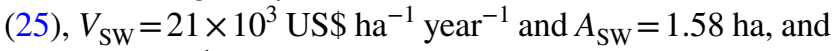
118 yen US $^{-1}$ for the exchange rate of the yen to the dollar (on December 11, 2014) are used. In addition, the damage is considered to be temporary because seaweeds can grow after the collision. Thus, the damage is assumed to persist for only 1 year, namely $Y_{\mathrm{R}}=1$ year in formula (25).

Finally, as for the oil storage facility, there are five oil storage ships with $880,000 \mathrm{~kL}$ of oil stored in each ship at Kamigoto Islands [32]. In this study, it is assumed that the drifting FOWT collides with one of the oil storage ships and all of the oil stored in the ship is spilt out, namely $V_{\mathrm{O}}=880,000 \mathrm{~kL}$ in formula (26). Also, it is assumed that the whole area of seaweed forest is polluted by the oil, namely $A_{\mathrm{SW}}=200$ ha in formula (27). Moreover, because the oil pollution can reach the soil into which the seaweed takes root, the damage of seaweed is considered to be prolonged. Tentatively, it is assumed that the necessary period for reinstatement, $Y_{\mathrm{R}}$, is 10 years in formula (27).

\subsubsection{Financial loss of the ships owing to collision with the drifting FOWT}

The charter fee of PANAMAX type bulk carrier is 8179 US\$ day $^{-1}$ (on December 11, 2014). On the other hand, as well

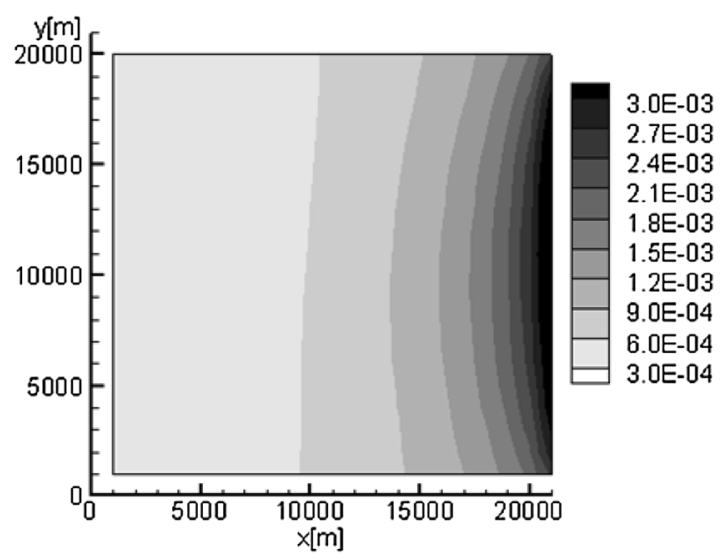

Fig. 8 Distribution of $p_{1}$ in the sea area "A" under the environmental conditions No. 1

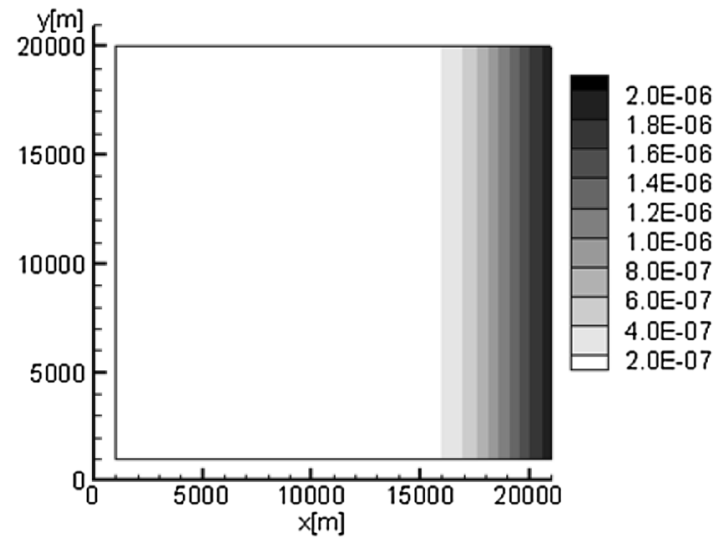

Fig. 9 Distribution of $p_{2}$ in the sea area "A"

as the case of the FOWT, the repair period depends on the availability of a dock or a repairing yard. The authors asked a ship repair company about the repair period and got the information: it takes about 22 days on average from the occurrence of accidents to the completion of repair works. 


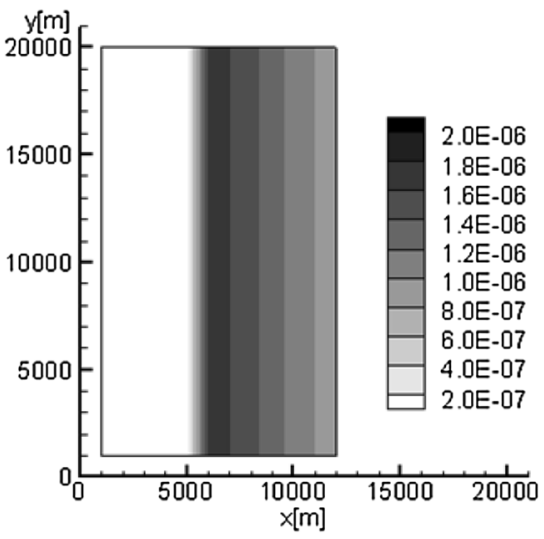

Fig. 10 Distribution of $p_{2}$ in the sea area "B"

Table 8 Minimum and maximum values of $p_{3 \_1}$ for each environmental condition

\begin{tabular}{lll}
\hline & \multicolumn{1}{c}{ Minimum value } & Maximum value \\
\hline Environmental conditions & \\
No. 1 & $5.31 \times 10^{-3}$ & $9.93 \times 10^{-3}$ \\
No. 2 & $1.65 \times 10^{-3}$ & $2.02 \times 10^{-3}$ \\
No. 3 & $2.77 \times 10^{-3}$ & $4.83 \times 10^{-3}$ \\
\hline
\end{tabular}

Thus, $V_{\mathrm{SU}}=8179 \mathrm{USS}$ day $^{-1}$ and $T_{\mathrm{S}}=22$ days in formula (28).

\subsection{Calculation results}

\subsubsection{Probability of each risk event}

The calculation conditions can be categorized into two types. One type of conditions uniformly affects the whole candidate area, and another type of conditions largely affects some areas and hardly affects other areas. The former conditions have impacts only on the magnitudes of the values, but not on the distributions, while the latter ones can change the distributions of the probabilities.

The impacts of the calculation conditions on the calculation results for each probability are shown in Table 7 and they are verified by considering the calculation results as shown below. However, the impacts of the ship size distribution are not verified because only one kind of ship size distribution is used for the calculations.

First, the distribution of $p_{1}$ depends on the environmental conditions because the drift directions of ships depend on the environmental conditions. Figure 8 shows the distribution of $p_{1}$ in the sea area "A", under the environmental conditions No. 1 . We confirmed the differences of the distributions of $p_{1}$ among the three kinds of environmental
Table 9 Values of $p_{32}$ for each combination of the environmental conditions and the ship speed distributions

\begin{tabular}{lll}
\hline & \multicolumn{2}{l}{ Ship speed distributions } \\
\cline { 2 - 3 } & Sea area "A" & Sea area "B" \\
\hline Environmental conditions & & \\
No. 1 & $4.26 \times 10^{-1}$ & $4.14 \times 10^{-1}$ \\
No. 2 & $4.38 \times 10^{-1}$ & $4.24 \times 10^{-1}$ \\
No. 3 & $4.40 \times 10^{-1}$ & $4.27 \times 10^{-1}$ \\
\hline
\end{tabular}

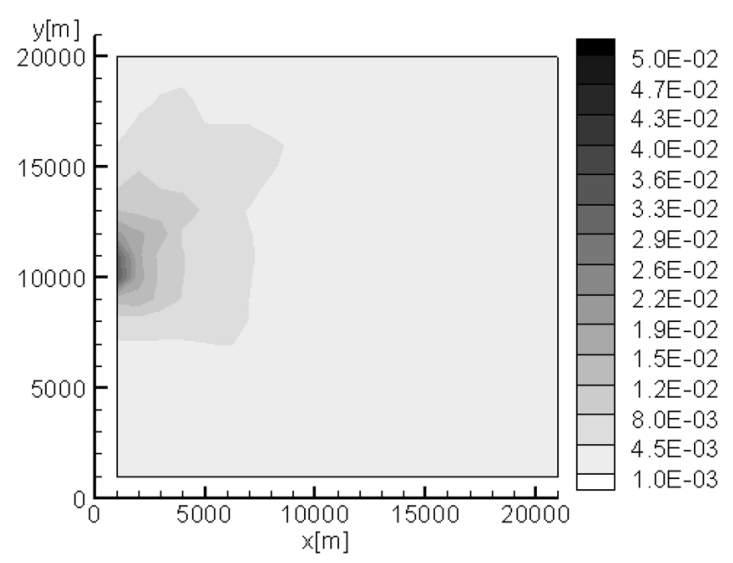

Fig. 11 Distribution of $p_{5}$ in the sea area "A" under the environmental conditions No. 1 and the fish preserves for seriola at $(0 \mathrm{~m}, 10000 \mathrm{~m})$

conditions. The values of $p_{1}$ are higher near the centerline of the sea-lane in all the cases.

Second, the distribution of $p_{2}$ depends on the lateral ship distribution. Figures 9 and 10 show the distributions of $p_{2}$ in the sea areas "A" and "B", respectively. The probability is determined by the distance from the centerline or the peak line of the sea-lane. In the case of Gaussian distribution (in the sea area "A"), the centerline of the sea-lane is at $x=22,000 \mathrm{~m}$ and the probability decrease gradually as the distance from the centerline becomes farther. On the other hand, in the case of gamma distribution (in the sea area "B"), the peak line is at about $x=6000 \mathrm{~m}$ and the probability decrease gradually as the distance from the peak line becomes farther in the east side of the peak line, while the probability decreases drastically and becomes almost zero in a short distance in the west side of the peak line.

Third, the distribution of $p_{3-1}$ depends on the environmental conditions and the ship size distribution, while the value of $p_{3 \_}$is not so much varied wherever the FOWT is installed in the candidate area. Table 8 shows the minimum and maximum values of $p_{3_{1} 1}$ for each environmental condition. In all the cases, the maximum values are less than twice of the minimum values. The reason is considered to be that the environmental conditions are uniform and the sizes of 


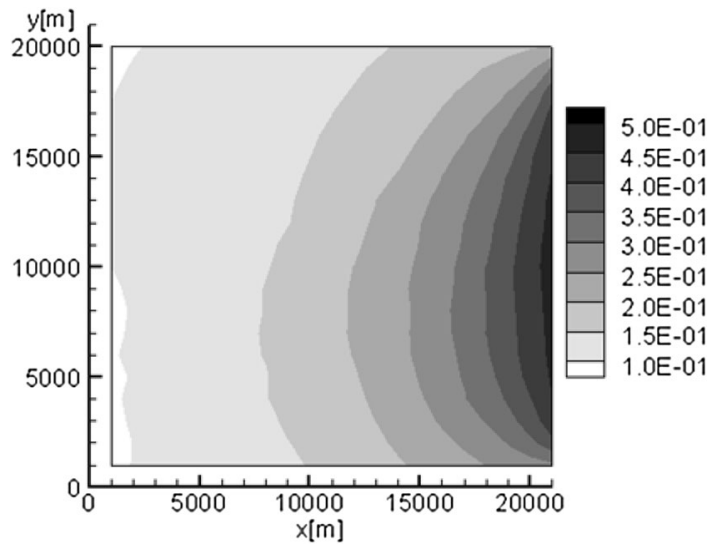

Fig. 12 Distribution of $p_{6}$ in the sea area "A" under the environmental conditions No. 1

drifting ships which collide with the FOWT are similar in the whole candidate area.

Fourth, the values of $p_{3 \_2}$ are independent of the position in the candidate area, but dependent on the environmental conditions and the distributions of ship speed and size. Table 9 shows the values of $p_{3 \_2}$ for each combination of the conditions. There are not so much differences among these combinations of conditions.

Fifth, the distributions of $p_{5}$ are affected by the environmental conditions because the drift direction of the FOWT is varied by them. Also, if the coastal facility or ecosystem is located in the other positions, the distributions of $p_{5}$ are changed. On the other hand, the magnitudes of the values of $p_{5}$ in the whole candidate area are varied by the types of the coastal facilities or ecosystem because the collision area is varied by the types. Figure 11 shows the distributions of $p_{5}$ in the sea area "A" under the environmental conditions No. 1 and the fish preserves for seriola at $(0 \mathrm{~m}, 10000 \mathrm{~m})$. In this figure, it can be found that the values of $p_{5}$ are higher near the fish preserves. The authors confirmed the differences under all the three environmental conditions and the four types and 20 locations of the coastal facility or ecosystem.

Sixth, the distribution of $p_{6}$ depends on the environmental conditions because the drift direction of the FOWT is varied by them. Figure 12 shows the distributions of $p_{6}$ in the sea area " $\mathrm{A}$ ", under the environmental conditions No. 1 . We confirmed the differences of the distributions of $p_{6}$ among the three kinds of environmental conditions. The values of $p_{6}$ were higher near the centerline of the sea-lane in all the cases.

Finally, because the values of $p_{4}$ and $p_{7}$ are set to be constant in this study, the values are independent of the position in the candidate area.

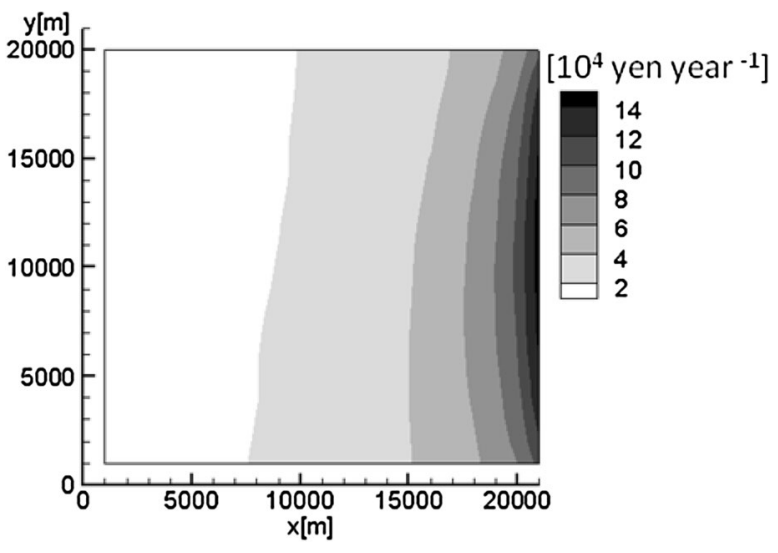

Fig. 13 Distribution of $r_{\mathrm{a}}$ in the sea area "A" under the environmental conditions No. 1 and the oil storage ships at $(0 \mathrm{~m}, 10000 \mathrm{~m})$

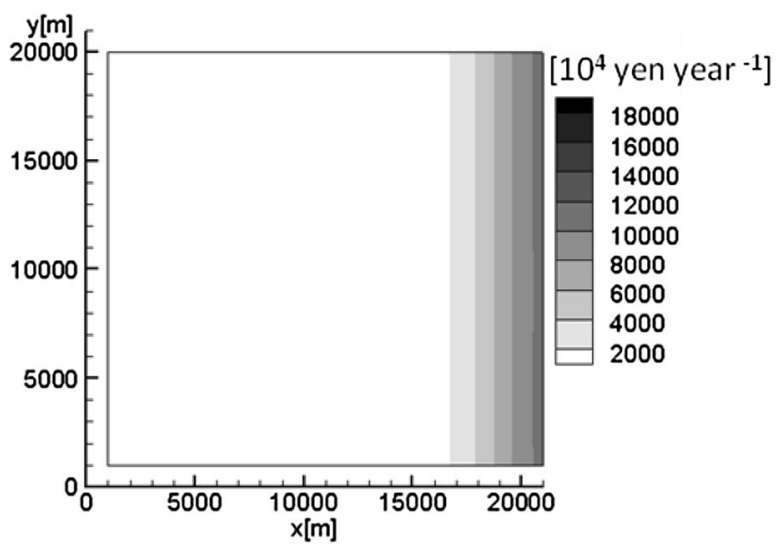

Fig. 14 Distribution of $r_{\mathrm{b}}$ in the sea area "A" under the environmental conditions No. 1 and the oil storage ships at $(0 \mathrm{~m}, 10000 \mathrm{~m})$

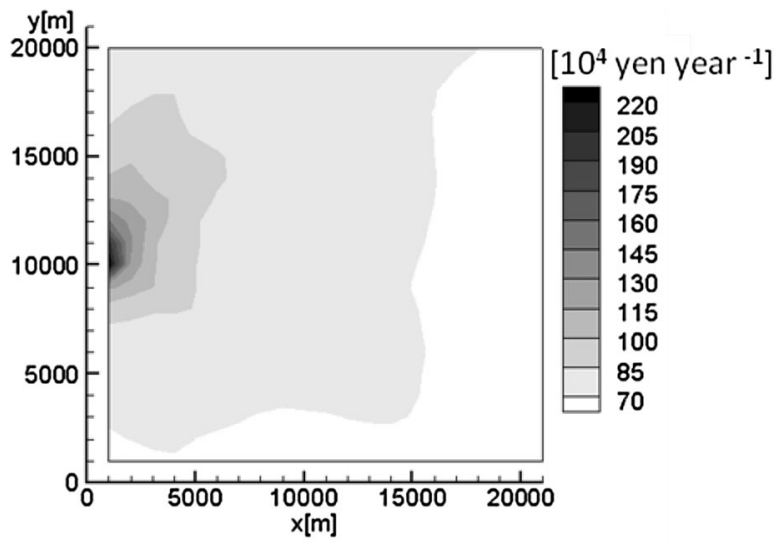

Fig. 15 Distribution of $r_{\mathrm{c}}$ in the sea area "A" under the environmental conditions No. 1 and the oil storage ships at $(0 \mathrm{~m}, 10000 \mathrm{~m})$ 


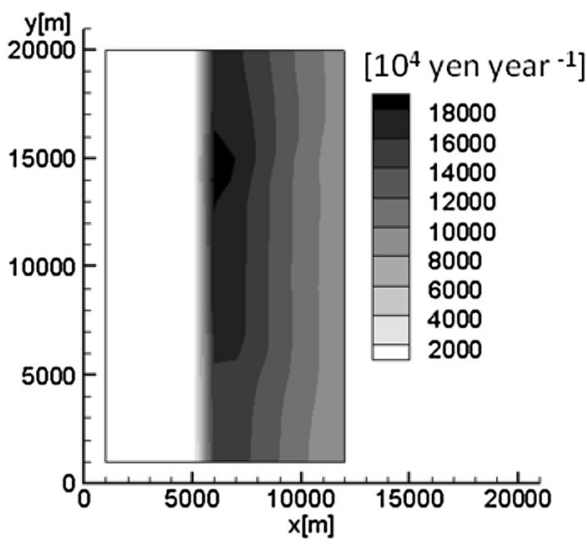

Fig. 16 Distribution of $r_{\mathrm{b}}$ in the sea area "B" under the environmental conditions No. 1 and the oil storage ships at $(0 \mathrm{~m}, 10000 \mathrm{~m})$

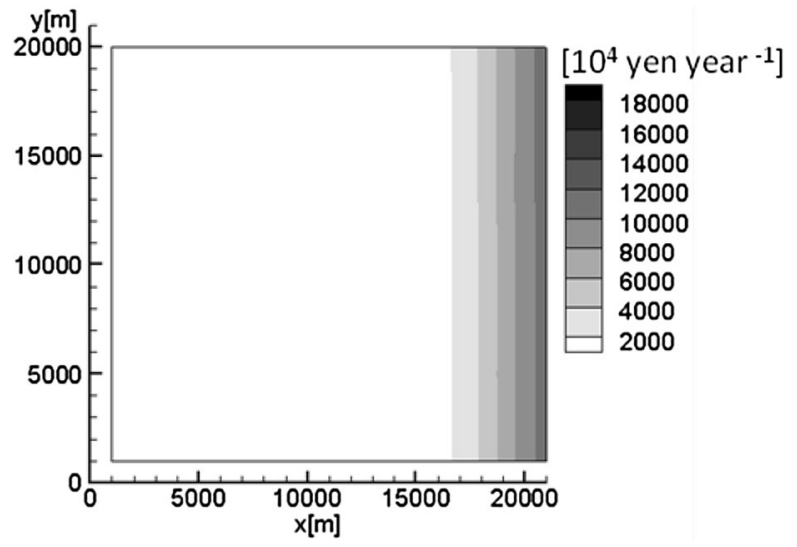

Fig. 17 Distribution of the whole risk in the sea area "A" under the environmental conditions No. 1 , and the oil storage ships at $(0 \mathrm{~m}$, $10000 \mathrm{~m}$ )

\subsubsection{Financial losses}

The calculated financial losses of the FOWT, coastal facilities and ecosystem are as follows:

$s_{1}=s_{2}=7600 \times 10^{4}$ yen,

$s_{3}=s_{4}=631,000 \times 10^{4}$ yen,

$s_{5 \mathrm{f}}($ seriola $)=32,000 \times 10^{4}$ yen,

$s_{5 \mathrm{f}}($ tuna $)=35,400 \times 10^{4}$ yen,

$s_{5 \mathrm{SW}}=391 \times 10^{4}$ yen,

$s_{5 \mathrm{O}}=9,310,000 \times 10^{4}$ yen,

$\mathrm{s}_{7}=1690 \times 10^{4}$ yen

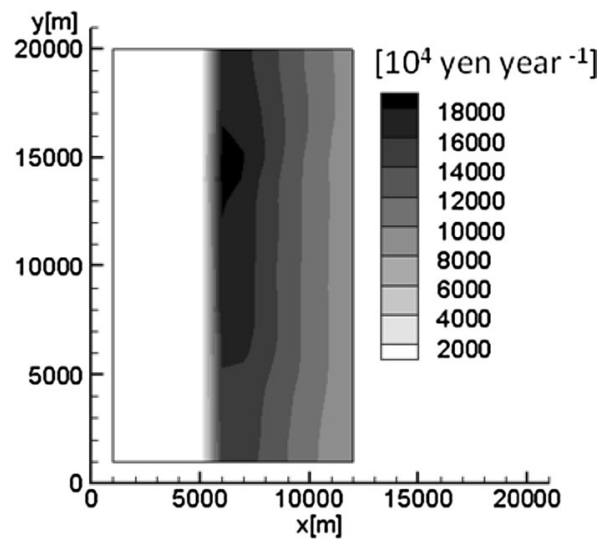

Fig. 18 Distribution of the whole risk in the sea area "B" under the environmental conditions No. 1 and the oil storage ships at $(0 \mathrm{~m}$, $10000 \mathrm{~m})$

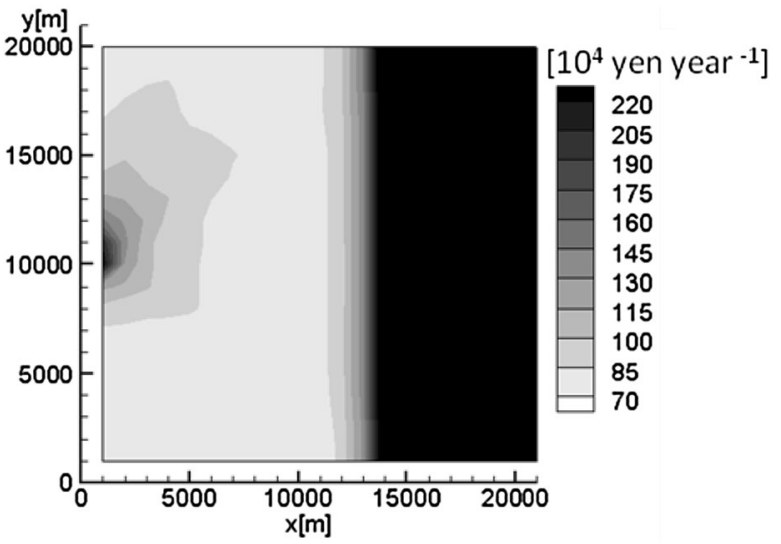

Fig. 19 Distribution of the whole risk in the sea area "A" under the environmental conditions No. 1 , and the oil storage ships at $(0 \mathrm{~m}$, $10000 \mathrm{~m}$ ), with the contours of lower band

\subsubsection{Risks}

As shown in Fig. 1, we considered the three trigger events, i.e., drift of a ship, wrong operation of a ship and unexpected environmental conditions. Hereafter, the risks corresponding to these trigger events are expressed by $r_{\mathrm{a}}, r_{\mathrm{b}}$ and $r_{\mathrm{c}}$, respectively, namely $r_{\mathrm{a}}, r_{\mathrm{b}}$ and $r_{\mathrm{c}}$ are the sub-totals of the risks $r_{1}-r_{6}, r_{7}-r_{12}$ and $r_{13}-r_{17}$ in formulae (29)-(45), respectively.

Figures 13,14 and 15 show the distributions of $r_{\mathrm{a}}, r_{\mathrm{b}}$ and $r_{\mathrm{c}}$ in the sea area "A" under the environmental conditions No. 1 and the oil storage ships at $(0 \mathrm{~m}, 10000 \mathrm{~m})$, respectively. In Figs. 13 and 14, it is clearly indicated that, in general, the nearer the distance to the centerline of the sea-lane is, the larger the risks $r_{\mathrm{a}}$ and $r_{\mathrm{b}}$ become, respectively. This tendency strongly appears especially in the distribution of 


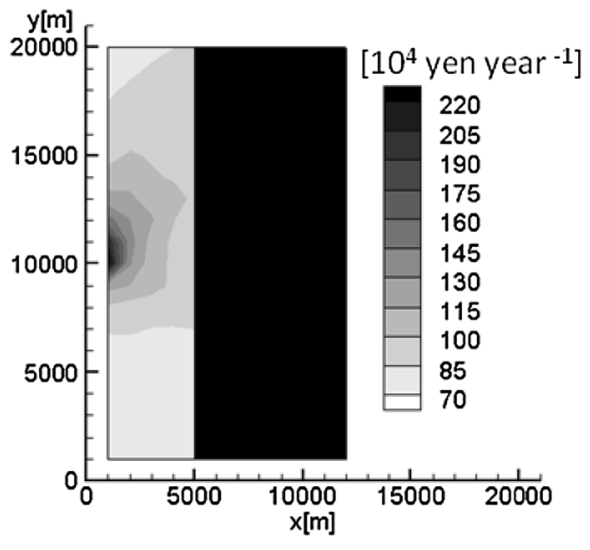

Fig. 20 Distribution of the whole risk in the sea area "B" under the environmental conditions No. 1 and the oil storage ships at $(0 \mathrm{~m}$, $10000 \mathrm{~m}$ ), with the contours of lower band

$r_{\mathrm{b}}$ : the values are nearly zero near the coastline, while the values are $10^{8}$ yen year ${ }^{-1}$ near the centerline of the sea-lane. On the other hand, this tendency does not seem to appear in the distribution of $r_{\mathrm{c}}$, as shown in Fig. 15, because the cause of drift of the FOWT is not related to ships in the sea-lane and the impact of $p_{5}$ appears clearly, instead.

In the sea area "B", the distributions of $r_{\mathrm{a}}$ and $r_{\mathrm{c}}$ are similar to those in the sea area "A", while the distributions of $r_{\mathrm{b}}$ have different characteristics. Figure 16 shows the distribution of $r_{\mathrm{b}}$ in the sea area "B" under the environmental conditions No. 1 , and the oil storage ships at $(0 \mathrm{~m}, 10000 \mathrm{~m})$. This figure indicates that the values of the risk are larger near the peak line (about $x=6000 \mathrm{~m}$ ) instead of the centerline of the sea-lane. In addition, the risks decrease gradually as the distance from the peak line becomes farther in the east side of the peak line, while the risks decrease drastically and becomes almost zero in a short distance in the west side of the peak line.

Moreover, Figs. 17 and 18 show the distributions of the whole risk, i.e., the total of all the risks in formulae (29)-(45). It was found that $r_{\mathrm{b}}$ was dominant on the whole risk and the same characteristic as that of $r_{\mathrm{b}}$ was recognized: the nearer the distance to the centerline or peak line of the sea-lane was, the larger the whole risk became. Even if the type or the location of a coastal facility or ecosystem is changed, this characteristic is not changed.

However, in the coastal area, $r_{\mathrm{c}}$ is dominant in the whole risk. Figures 19 and 20 are the distributions of the whole risk in the sea areas "A" and "B", respectively, under the same conditions as in Figs. 17 and 18, respectively, with the contours of lower band. If the type or the location of a coastal facility or ecosystem is changed, the magnitude or distribution of the whole risk will also be changed clearly in the coastal area where the risks related to the sea-lane are small enough.

\section{Discussion}

\subsection{Impacts of the sea-lane and the coastal facilities or ecosystem on the distribution of the whole risk}

In the distribution of the whole risk, i.e., the whole risk maps, the risks near the sea-lane are much larger than those near the coastal facility or ecosystem. Even if the financial loss of the coastal facility or ecosystem, i.e., $s_{5}$, is much higher, the risks near the sea-lane will also be higher because the collision between the drifting FOWT and the coastal facility or ecosystem results from drift of the FOWT, whose probability is higher near the centerline or the peak line of the sea-lane. In other words, in formulae (29) and (35), if $s_{5}$ increases, $r_{1}$ and $r_{7}$ will also increase. $r_{1}$ and $r_{7}$ near the sea-lane are much larger than those near the coastal facilities or ecosystem because $p_{1}$ and $p_{2}$ near the sea-lane are higher than those in the coastal area. Therefore, even if $s_{5}$ increases, the whole risk will increase in the whole candidate area and there is no change to the fact that the whole risk near the sealane is larger than near the coastal facility or ecosystem.

However, as mentioned in Sect. 4.2.3, it is possible to identify the impacts of the risk corresponding to the collision between the drifting FOWT and the coastal facility or ecosystem on the whole risk map when we focus only on the area where the risks related to the sea-lane are small enough.

\subsection{Uncertainties of the model}

There are uncertainties in the models established in this study owing to the lack of available data. The data necessary for improvement of the models are as follows:

1. probability of drift of ships;

2. probability of wrong operation of ships;

3. probability of drift of the FOWT by unexpected environmental conditions;

4. breaking load of the mooring chain

5. probability of collision between the drifting FOWT and a ship in the sea-lane;

6. financial loss of the FOWT's repair; and

7. financial losses of coastal facilities or ecosystem. 
Although these data are necessary to improve reliability of the models, it is difficult to obtain these data. Then the impacts of these uncertainties are verified below.

First, the impacts of the uncertainties related to No. 1, 2 and 3 above are verified. As for No. 1 and 2, it is difficult to find whether the real probabilities are higher or lower than the values set in this study, but the value of No. 3 is likely to be overestimated because it is the standard for one mooring chain not to be broken. As mentioned in Sect. 4.2.3, the risks $r_{\mathrm{a}}, r_{\mathrm{b}}$, and $r_{\mathrm{c}}$ are corresponding to No. 1, 2 and 3, respectively. We verified how much impact was on the relations among the magnitudes of these risks if the value of No. 3 was lower than that was set in this study.

In the case that the lateral ship distribution is approximated to Gaussian, the risk $r_{\mathrm{b}}$ is dominant near the centerline of the sea-lane and the risk $r_{\mathrm{c}}$ is dominant near the coastline. If the value of No. 3 is lower, only the risk $r_{\mathrm{c}}$ gets lower. Thus, even if the value of No. 3 is much lower, the risk $r_{\mathrm{b}}$ is still dominant near the centerline of the sea-lane. Also, the risk $r_{\mathrm{c}}$ is still dominant near the coastline if the value of No. 3 is only one order of magnitude lower. However, if the value is two or more orders of magnitudes lower, the risk $r_{\mathrm{c}}$ becomes smaller than the risk $r_{\mathrm{a}}$ in the most area. Nevertheless, we can identify the distribution of the risk corresponding to the collision between the drifting FOWT and the coastal facility or ecosystem on the whole risk map when we focus only on the coastal area.

On the other hand, in the case that the lateral ship distribution is approximated to gamma distribution, the verification results are almost the same as Gaussian distribution. The difference is only "centerline" and "peak line" of the sea-lane.

Second, the value of No. 4 can be changed over time and become lower than the MBL owing to aging degradation as mentioned above. It is necessary to take account of the change of the braking load as time elapses for more accurate assessment. However, if the breaking load is lower than the MBL, $p_{31}$ and $p_{32}$ get larger and risks related to the sealane will also get larger. Therefore, there would be no change to the fact that the whole risk is larger near the centerline of the sea-lane than near the coastline.

Third, the impact of the uncertainty of the value of No. 5, i.e., p7, was verified by changing its orders of magnitude. As a result, even if this value was three orders of magnitude higher or lower, there was little impact on the whole risk map.

Fourth, the impact of the uncertainty of the value of No. 6 , i.e., $s_{1}$ and $s_{2}$, was verified. Because the FOWT may not be repaired for a long time in a peak season of shipbuilding, $s_{1}$ and $s_{2}$ can possibly be longer than the value set in the case study. Then we changed the values from 44 days to 1 or 2 years, but the impacts of the changes were small enough to be negligible.
Finally, as mentioned above, if the value of No. 7 , i.e., $s_{5}$, becomes larger, the whole risk will also become larger in the whole candidate area, and there will be little impact on the distribution of the whole risk.

Accordingly, these uncertainties seem to have little impact on the procedures for site selection established in this study mentioned in Sect. 6, but it will be the future tasks to collect the data and consider more accurate estimation methods.

Moreover, the drift directions of ships and the FOWT are calculated with steady-state environmental conditions in this study, while the environmental conditions can be changed during drifts and the drift directions can be also changed. Therefore, the nonsteady calculations will be needed for more accurate estimation. In the case of nonsteady calculations, even if the environmental conditions are the same at the beginning of drifts, they can be changed in so many ways that it will be necessary to conduct the statistical calculations, such as Monte Carlo simulations.

\section{Conclusions}

In this paper, the authors proposed the method of quantitative risk assessment to select an appropriate position for installing a FOWT, taking account of the spatial relations with surrounding sea-lanes, coastal facilities and ecosystem. Then we showed the calculation results in the case study of the quantitative risk assessment.

Based on the calculation results in the case study, it is recommended to apply the following procedures when selecting an appropriate position for installing a FOWT taking account of safety risks:

first, extract the area where the risks related to the sealane are small enough: the distance from the centerline or peak line of the sea-lane is large enough; and

second, select the position within the extracted area with the smallest risk of collision with coastal facilities or ecosystem in case of drift of the FOWT by quantitative evaluation of the risk distribution under the environmental conditions in the area.

In both the areas with the lateral ship distribution approximated to Gaussian and gamma distributions, the number of ships decreases gradually or drastically in a certain distance from the centerline or peak line of the sea-lane, and the risks related to the sea-lane become to have little impacts near the coastline on the risk map. Because there are a lot of such areas in Japanese coast, it is appropriate to select the position with the smallest risk corresponding to collision with coastal facilities or ecosystem within the area where the risks related to the sea-lane are small enough. 
Accordingly, in this study, the above procedure is proposed as the method of site selection for installing a FOWT, which is commonly applicable for most areas in Japanese coast.

Acknowledgements The authors would like to express appreciation to Dr. Hiroko Itoh for her instructions about risk analysis. The analyzed AIS data were provided by Dr. Hiroko Itoh and Ms. Emiko Takanashi and the statistical database for maritime weather was provided by Mr. Tomoki Taniguchi. The authors gratefully acknowledge them for providing data and instructions. Dr. Shunji Inoue and Dr. Toshifumi Fujiwara provided helpful advice for this study and Dr. Susumu Ota proofread this paper. The authors would like to thank them for their cooperation.

Open Access This article is distributed under the terms of the Creative Commons Attribution 4.0 International License (http://creativeco mmons.org/licenses/by/4.0/), which permits unrestricted use, distribution, and reproduction in any medium, provided you give appropriate credit to the original author(s) and the source, provide a link to the Creative Commons license, and indicate if changes were made.

\section{References}

1. GOTO FOWT (2018) GOTO FOWT floating offshore wind turbine, [Online]. http://goto-fowt.go.jp/. Accessed 2 Oct 2018

2. Utsunomiya T, Sato I, Shiraishi T, Inui E, Ishida S (2014) Toward the commercialization of floating offshore wind power generation-the demonstration project in Goto Kabashima [Japanese]. J Jpn Soc Civil Eng B3 70(2):I_1-I_6

3. Fukushima Offshore Wind Consortium (2018) Fukushima FORWARD [Online]. http://www.fukushima-forward.jp/english/index .html. Accessed 3 July 2018

4. Det Norske Veritas AS (2013) Design of floating wind turbine structure, offshore standard DNV-OS-J103. https://rules.dnvg1 .com/docs/pdf/DNV/codes/docs/2013-06/OS-J103.pdf

5. Maritime Bureau of Ministry of Land, Infrastructure, Transport and Tourism, National Maritime Research Institute and The University of Tokyo (2014) Safety guidelines for technical standards for floating offshore wind turbines [Japanese]. Maritime Bureau of MLIT, Japan

6. Suzuki H, Kurimoto M, Kitahara Y, Fukumoto Y (2009) A study on scenario and risk of progressive drifting of spar-typed floating wind turbines in a wind farm [Japanese]. Wind Energy Bull Jpn Wind Energy Assoc 33(3):96-103

7. Kitahara Y, Suzuki H, Enomoto K, Fukumoto Y (2010) Risk assessment of progressive drifting of floating wind turbines in a wind farm [Japanese]. Proc Wind Energy Utilization Symp Jpn Wind Energy Assoc 32:183-186

8. Bauer L, Matysik S (2018) Gamesa G128-5.0 MW offshore [Online]. https://en.wind-turbine-models.com/turbines/767-games a-g 128-5.0mw. Accessed 3 Oct 2018

9. National Maritime Research Institute, The University of Tokyo (2013) Report of 'Study on Safety of Floating Offshore Wind Turbines' (FYH 23) [Japanese]

10. Domon A, Izumiya T, Ishibashi K (2012) Study on the drag coefficient ratio of drifting objects due to wind and waves and prediction of leeway trajectory [Japanese]. J Jpn Soc Civil Eng B3 68(No. 2):I_1031-I_1036

11. Ueno M, Nimura T, Miyazaki H (2002) On steady drifting motion of disabled ships [Japanese]. Soc Naval Archit Jpn 192:103-111

12. Haugen S, Moan T (1991) Probabilistic evaluation of frequency of collision between ships and offshore platforms. International
Association for Civil Engineering reliability and risk analysis, sixth international conference on applications of statistics and probability in civil engineering Mexico City, Mexico, pp 977-984

13. Haugen S, Moan T (1992) Frequency of collision between ships and platforms. OMAE—-safety and reliability, vol 2. ASME, New York, pp 389-365

14. Vinnem JE (2014) Collision risk modelling. In: Pham H (ed) Offshore risk assessment vol 1 principles, modelling and applications of QRA studies (Chap 9), 3rd edn. Springer, New York, pp 313-367

15. Shoji K (1975) Study on the motion of moored body and the tension of mooring lines [Japanese]. J Soc Naval Archit Jpn 1975(138):233-246

16. Taniguchi T, Ishida S, Fujiwara T, Inoue S (2016) A study on energy potential and safety evaluation factor for ocean renewable energy [Japanese]. Papers Natl Marit Res Inst 16(2):71-105

17. International Organization for Standardization (2013) Petroleum and natural gas industries - specific requirements for offshore structures-part 7: station keeping systems for floating offshore structures and mobile offshore units. ISO 19901-7:2013(E), Switzerland

18. Ushiyama I (2013) Introduction to windmill engineering [Japanese], 2nd edn. Morikita Publishing, Tokyo

19. Ushiyama I (2005) Basis of wind energy [Japanese]. Ohmsha, Tokyo

20. Jonkman J, Butterfield S, Musial W, Scott G (2009) Definition of a 5-MW reference wind turbine for offshore system development. Technical Report NREL/TP-500-38060

21. Ishihara T, Honda A, Yoshida S, Kubo N (2010) Assessment of wind loads [Japanese]. In: Ishihara T (ed) Guidelines and manuals for structural design of wind turbine support structure, 2010 edn, Chap. 4, Japan Society of Civil Engineering, pp 77-150

22. Odano N, Sawada K, Mochiduki H, Hirao Y, Asami M (2010) Research on risk assessment for maritime transport of radioactive materials: preparation of maritime accident data for risk assessment [Japanese]. Papers Natl Marit Res Inst 10(3):93-106

23. Kaneko F (2012) FSA related matter [Japanese]. Papers Natl Marit Res Inst 12(4):31-42

24. Takahashi H, Goto A, Abe M (2006) Study on ship dimensions by statistical analysis - standard of main dimensions of design ship (draft) [Japanese]. Research Report of National Institute for Land and Infrastructure Management, No. 28

25. Itoh H, Takanashi E (2014) Private communications

26. Itoh H, Yakabe F (2014) Modeling ship traffic distributions in coastal areas [Japanese]. J Jpn Soc Naval Archit Ocean Eng 19:235-244

27. Japan Coast Guard (2017) Current situation and measures for maritime casualty (H 28 version) [Japanese]

28. Ministry of Land, Infrastructure, Transport and Tourism (2018) Harbor statistics (annual report) H28 [Japanese] [Online]. http://www. mlit.go.jp/k-toukei/01/annual/nenpou0.pdf. Accessed 12 Oct 2018

29. Agency for Natural Resources and Energy, Ministry of Economy, Trade and Industry (2018) Feed-in Tariff system for renewable energy [Japanese] [Online]. http://www.enecho.meti.go.jp/categ ory/saving_and_new/saiene/kaitori/fit_kakaku.html. Accessed 7 June 2018

30. National Research Institute of Fisheries Engineering, Japan Fisheries Research and Education Agency (2007) Form of offshore fish-raising [Japanese], meeting document of utilization WG of $R \& D$ project of offshore platform

31. Shoji J (2013) Assessment of economic value of seaweed forests as ecosystem services: search for 'top of Japan' from 'prime cost' of fishery production [Japanese], final report of Environment Research and Technology Comprehensive Information (RF-0907(1))

32. Kamigoto Oil Storage Company, Ltd. (2018) Oil storage facilities [Japanese] [Online]. http://www.kamigoto.co.jp/facility/index .html. Accessed 2 Oct 2018 